\title{
ASE Noise Characterization of an All-Fiber Sagnac Interferometer via LAN for Remote Sensing
}

\author{
Abraham Sierra-Calderon', Jose Carlos Rodriguez-Novelo', Manuel May-Alarcon'2, \\ Jaime Rafael Ek-Ek ${ }^{1}$, Jose Alfredo Alvarez-Chavez ${ }^{1,3^{*}}$, Herman Leonard Offerhaus ${ }^{3}$ \\ ${ }^{1}$ Centro de Investigacion e Innovacion Tecnologica, Instituto Politecnico Nacional, \\ Mexico City, Mexico \\ ${ }^{2}$ Facultad de Ingenieria, Universidad Autonoma del Carmen, Ciudad del Carmen, Mexico \\ ${ }^{3}$ Optical Sciences Group, University of Twente, Enschede, The Netherlands \\ Email: ${ }^{*}$ j.a.alvarezchavez@utwente.nl
}

How to cite this paper: Sierra-Calderon, A., Rodriguez-Novelo, J.C., May-Alarcon, M., Ek-Ek, J.R., Alvarez-Chavez, J.A. and Offerhaus, H.L. (2018) ASE Noise Characterization of an All-Fiber Sagnac Interferometer via LAN for Remote Sensing. Open Journal of Applied Sciences, 8, 554-575. https://doi.org/10.4236/ojapps.2018.812045

Received: November 6, 2018 Accepted: December 4, 2018

Published: December 7, 2018

Copyright $\odot 2018$ by authors and Scientific Research Publishing Inc. This work is licensed under the Creative Commons Attribution International License (CC BY 4.0).

http://creativecommons.org/licenses/by/4.0/

\begin{abstract}
The spectral noise characteristic and relative intensity noise of an all-fibre Sagnac interferometer consisting of pump source, a WDM, a piece of Er-doped fibre, a fibre Bragg grating (FBG), an optical circulator and a 50/50 coupler, were studied over a 75C-degree range. At the probing end, a high-birefringence piece of fibre and a Peltier were employed for temperature variation. Spectral and temperature response of the noise reduction due to temperature variation was performed remotely using an Arduino micro-controller and a DS18B20 digital sensor and fed into a local area network. Optical and thermal characterization of the system has also been undertaken.
\end{abstract}

\section{Keywords}

Amplified Spontaneous Emission Noise, Sagnac Interferometer, Optical Fibre Sensor, Erbium-Doped Fibre Amplifier, Fibre Bragg Grating

\section{Introduction}

Light propagation through optical fibers does not only have applications in optical communications for data transmission. It also has different applications such in Medicine, Industry and other areas as pressure, temperature, stress and torsion sensors [1] [2]. Therefore, remote control of optical characterization is very important both at system and component levels.

Groups of fibres that connect to different optical components are called optical arrays. In this research work, two optical arrays were employed: An Erbium 
Doped Fibre Amplifier (EDFA) and a Sagnac interferometer (SI). The two optical arrays have different optical components and these arrays were characterized optically as they are inserted into the system. Characterization results on amplified spontaneous emission (ASE) noise of the separate components were investigated. Due to harsh weather conditions in our labs, remote temperature characterization through a local area network (LAN), is very important as the user could be located far from the experiment and in this way, the birefringent fibre temperature can still be known. The proposed LAN works under a client-server architecture in order to reduce the time employed for users during the component and system characterization of temperature.

\section{Experiments}

\subsection{Characterization of Optical Arrays}

The first optical array (seen in Figure 1) was the main setup for temperature characterization. It consists of an Erbium-doped fiber amplifier (EDFA), an optical circulator for measuring the reflected and transmitted power, and a Sagnac interferometer (SI). A QFBGLD980-250 laser at $980 \mathrm{~nm}$ with $51 \mathrm{~mA}$ of threshold, a WDM with $\leq 0.3 \mathrm{~dB}$ of insertion loss, 0.22 of numerical aperture (NA), an Erbium doped fibre with a 980 and $1480 \mathrm{~nm}$ pump wavelength and 1530 1610 emission on C and L bands and a FBG at $1548.4 \mathrm{~nm}$ conform the EDFA. The optical circulator was used to propagate the light on the clockwise direction. Finally, the SI was built with a 50/50 coupler with $21.6 \mathrm{~dB} / 0.4 \mathrm{~dB}$ of insertion loss, $\pm 40 \mathrm{~nm}$ of bandwidth, a Hi-Bi SHB1500 optical fibre used for the thermal sensor with a $0.13-0.16 \mathrm{NA}$, a Peltier board used to increase the temperature of the Hi-Bi fibre.

The main purpose of this optical array is to study the operation of each component with respect to their data sheets via spectral characterization with an optical spectrum analyser (OSA). The main optical array is shown in Figure 1.

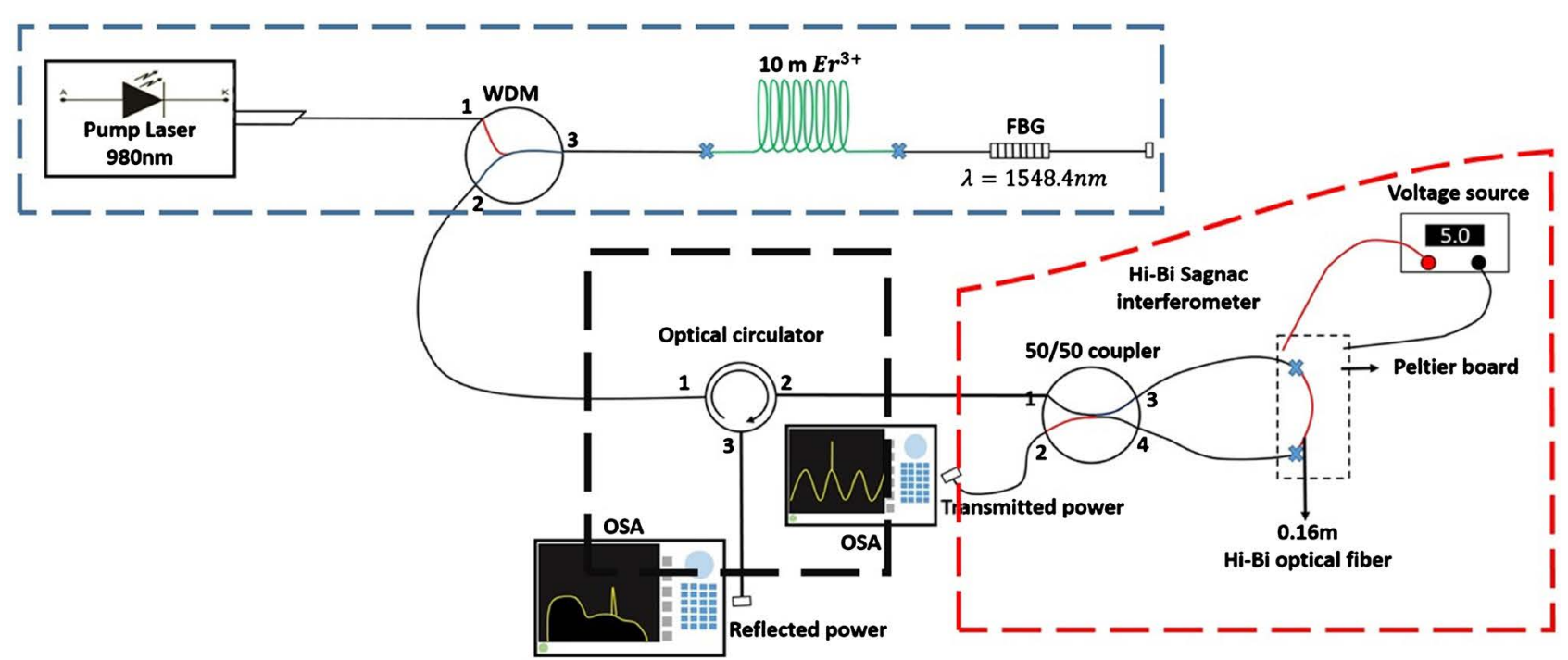

Figure 1. Signal amplification at $980 \mathrm{~nm}$ in blue, optical circulator in black and ASE noise reduction with temperature in red. 
The EDFAs components are shown in Figure 2. First, a $980 \mathrm{~nm}$ laser pump injects light into a standard fibre up to a Wavelength Division Multiplexer (WDM). The light then enters into port number one and gets out through port three towards the Erbium doped fibre, where it gets converted from $980 \mathrm{~nm}$ to $1550 \mathrm{~nm}$ [3] [4]. The amplified light propagates until it reaches the fibre Bragg grating (FBG) where it reflects light at $1548.4 \mathrm{~nm}$. One should note that his optical array does not use a transmitted laser signal [5] [6]. Finally, the reflection signal reaches ports two and three of the WDM and then it reaches the SI.

The next spectral characterization will include the EDFA with an optical circulator, as shown in Figure 3. The optical circulator is a component that propagates the light only in one direction so it is used to avoid light reflection from the optical fibre. Port number 2 is employed for measuring transmitted power, and port number three for reflected power.

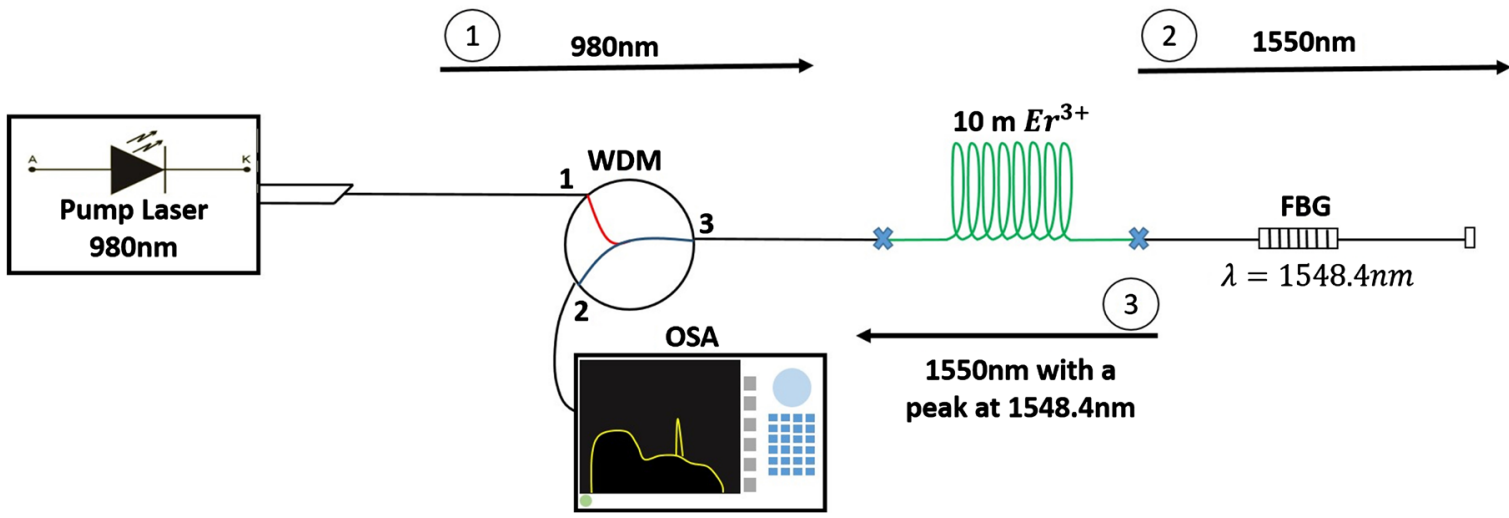

Figure 2. Spectral ASE noise measurement of reflected power.
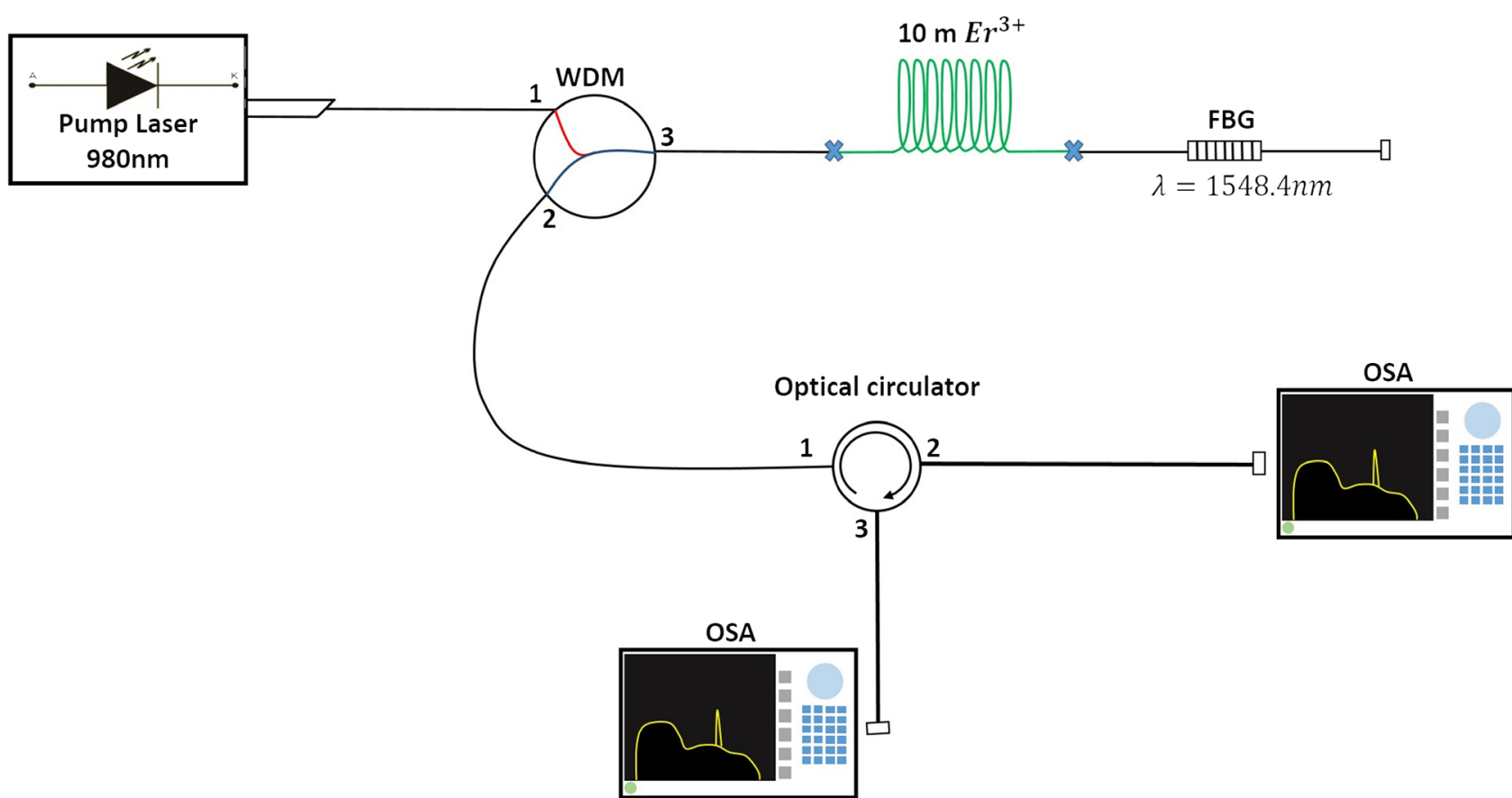

Figure 3. EDFA components with an optical circulator. 
According to Figure 2, spectral characterization has been performed from EDFA the reflected power, at different pump power values. Such EDFA system consists on a $980 \mathrm{~nm}$ pump source, a WDM coupler, $10 \mathrm{~m}$ of Er-doped fibre and a fibre Bragg grating at $1548.4 \mathrm{~nm}$.

The setup that includes a Sagnac interferometer is shown in Figure 4. It consists of a 50/50 coupler that has two input ports and two output ports. In port number one the input power is produced by the EDFA and the 50/50 coupler sends $50 \%$ to port three and $50 \%$ to port four. Signal from port three is propagated in the clockwise direction and the signal from port four is propagated in the anti-clockwise direction. The signal power is propagated into the $0.22 \mathrm{~m}$ high birefringence fibre (HI-BI). Finally, the signal power arrives to the 50/50 coupler and reflected power can be measured at port number one. The EDFA generates ASE noise that is measured at port number two, since it is an effect that is always generated when a pump of $980 \mathrm{~nm}$ is applied to an Erbium doped fibre [7] [8]. The photons that enter it are absorbed and create a transition from ground level to the excited level. Moreover, since the lifetime of photons in the excited level is around one $\mu$ s and the metastable level of its lifetime is about 10 $\mathrm{ms}$, there is a significant difference between the two lifetimes, and the electrons return from excited level to metastable level after one $\mu$ s, but light is not emitted. On the contrary, as the metastable level has a longer lifetime; if the pump signal is constant, population inversion is produced, and energy is stored between the metastable energy level and the ground level. When this energy relaxes, it produces both signal amplification at $1550 \mathrm{~nm}$ via stimulated emission and spontaneous emission [9] [10]. This ASE level is amplified, producing the ASE noise, as sketched in Figure 2. Furthermore, in order to remove the ASE noise, the SI optical array was setup as explained above.

Results on Figure 3 show that all wavelengths from 1500 to $1600 \mathrm{~nm}$ have been propagated from port 1 to port 2. By comparison from Figure 9 to Figure 10 , one can note that power levels at $1530 \mathrm{~nm}$ are very similar in both, but power is slightly higher at $1548.4 \mathrm{~nm}$, at the same current in the pump. One explanation is that power at this wavelength is reflected a few times by the Bragg grating,

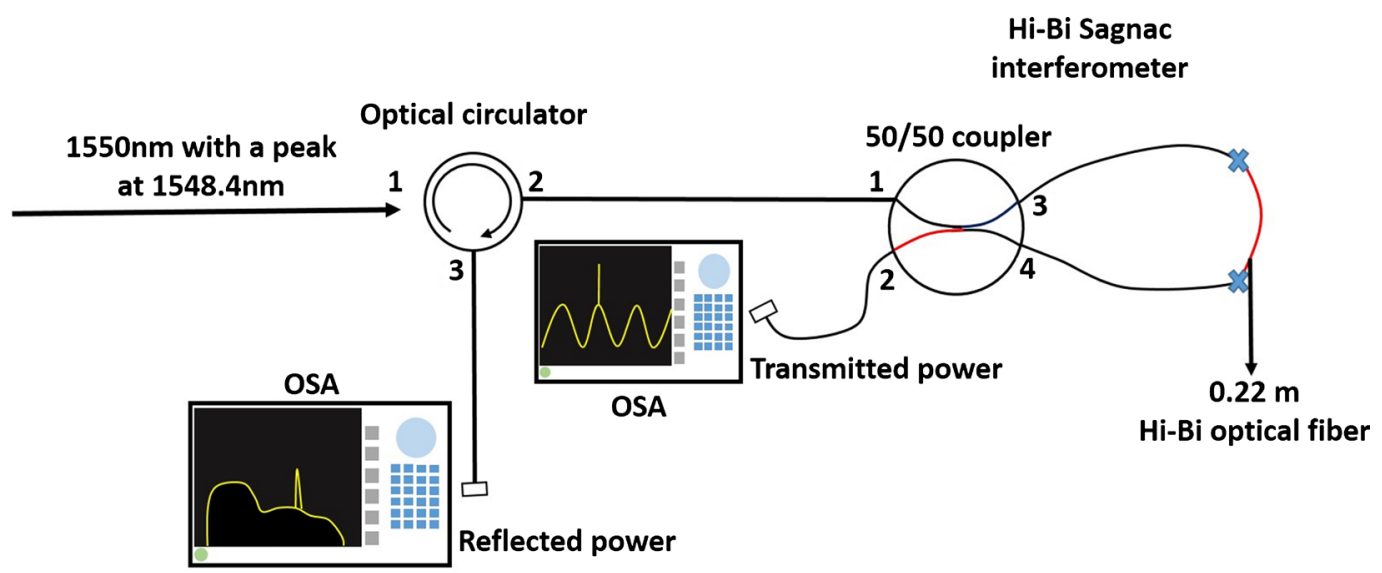

Figure 4. Sagnac interferometer. 
so it obtains considerable amplification within the EDFA.

From the previous figure, spectral characterization of port 2 at the 50/50 coupler and port 3 of the optical circulator has been performed. Power transmitted through the SI is obtained at port 2 of the coupler, while at port 3 of the circulator, the reflected power from the interferometer is obtained. Such interferometer consists on a 50/50 coupler and $0.22 \mathrm{~m}$ of $\mathrm{Hi}-\mathrm{Bi}$ fibre, both operating at room temperature. As it could be seen in Figure 12, the transmitted power of the SI shows 4 valleys due to the Hi-Bi fibre length. It can also be observed that ASE noise level is relatively high at 1530 and that at $1548.4 \mathrm{~nm}$ the power is considerably high too. The aforementioned figures were obtained at pump current values ranging from 10 to $200 \mathrm{~mA}$, in all cases.

ASE noise can be reduced through an SI, which at first indicates the need for temperature characterization of the aforementioned SI. As shown in Figure 4, a piece of Hi-Bi fiber spliced between port 3 and 4 of the SI for temperature modulation purposes using a Peltier.

\subsection{Characterization with Respect to Temperature}

The optical array presented in Figure 1 shows characteristics that affect the transmission power via ASE noise. This generates relatively high losses. In order to reduce most of the noise generated by the EDFA and in order to increase the transmission power, the optimization of optical array was done first, this process was also called "signal amplification at $1550 \mathrm{~nm}$ and ASE noise reduction" and then a temperature study of Sagnac interferometer, was included. At the output port of the coupler, the array was reduced to two splices and the Hi-Bi fibre was reduced to $16 \mathrm{~cm}$ to eliminate most $\mathrm{ASE}$ noise, this length of $\mathrm{Hi}-\mathrm{Bi}$ fibre is calculated using the following equation [11] [12]:

$$
L=\frac{\lambda^{2}}{(\Delta \lambda)(\Delta n)}
$$

where:

$L=\mathrm{Hi}-\mathrm{Bi}$ fibre length, in $\mathrm{m}$.

$\lambda=$ Wavelength of transmitted power, in $\mathrm{nm}$.

$\Delta \lambda=$ Period of valleys in the transmitted power curve, in $\mathrm{nm}$.

$\Delta n=$ Difference between the slow and fast axes in the Hi-Bi.

$$
\Delta \lambda=\left(\lambda_{2}-\lambda_{1}\right) \cdot n_{\max }
$$

where:

$\Delta \lambda=$ Transmittance period, in $\mathrm{nm}$.

$\lambda_{1}=$ Wavelength of a transmitted power valley, in $\mathrm{nm}$.

$\lambda_{2}=$ Wavelength of an adjacent transmitted power valley, in $\mathrm{nm}$.

$n_{\max }=$ number of peaks between $\lambda_{1}$ and $\lambda_{2}$.

Equation (2) was used to calculate the transmitted power period, as shown in Equation (3):

$$
\Delta \lambda=(1548.4 \mathrm{~nm}-1530.3 \mathrm{~nm}) *(2)
$$




$$
\Delta \lambda=36.2 \mathrm{~nm}
$$

Equation (1) was used to calculate the Hi-Bi fibre length, as shown in Equation (4):

$$
\begin{gathered}
L=\frac{(1548.4 \mathrm{~nm})^{2}}{(36.2 \mathrm{~nm})\left(4.22 \times 10^{-4}\right)}=0.1569 \\
L=0.16 \mathrm{~m}
\end{gathered}
$$

The second step relies on the controlled temperature for the SI, in order to reduce most of the ASE noise, for this reason it is necessary to characterize the temperature in the SI, when temperature control is added to $\mathrm{Hi}-\mathrm{Bi}$ fibre it changes its characteristics for contracting or dilating [13] [14]. A Peltier plate was employed for changing the fibre temperature characteristics. A variable voltage source is inserted into the plate for applying hot and cold periods into the $\mathrm{Hi}-\mathrm{Bi}$ fibre. The ASE noise reduction occurs when the signal to be filtered is introduced into the SI, which delivers precisely a filtered signal at a certain wavelength and rejects other signals at different wavelengths. In Figure 5 the improved optical array is shown, with the Peltier plate and the voltage source.

\subsection{Temperature Measurement}

The SI with a DS18B20 temperature sensor and an Arduino MEGA2560 plaque inside a LAN is observed in Figure 6. In order to induce temperature cycles to the Hi-Bi fibre, a Peltier plaque and a voltage source were employed. These temperature changes are transmitted to the DS18B20 temperature sensor, which was then connected to the Arduino MEGA2560 and a server. The temperature data are displayed in the computer screen by the user. Then, these data are sent to the computer, where the user does the measuring inside the LAN via remote access. Therefore, it is not necessary for the user to be physically in the optical array in order to characterize the temperature.

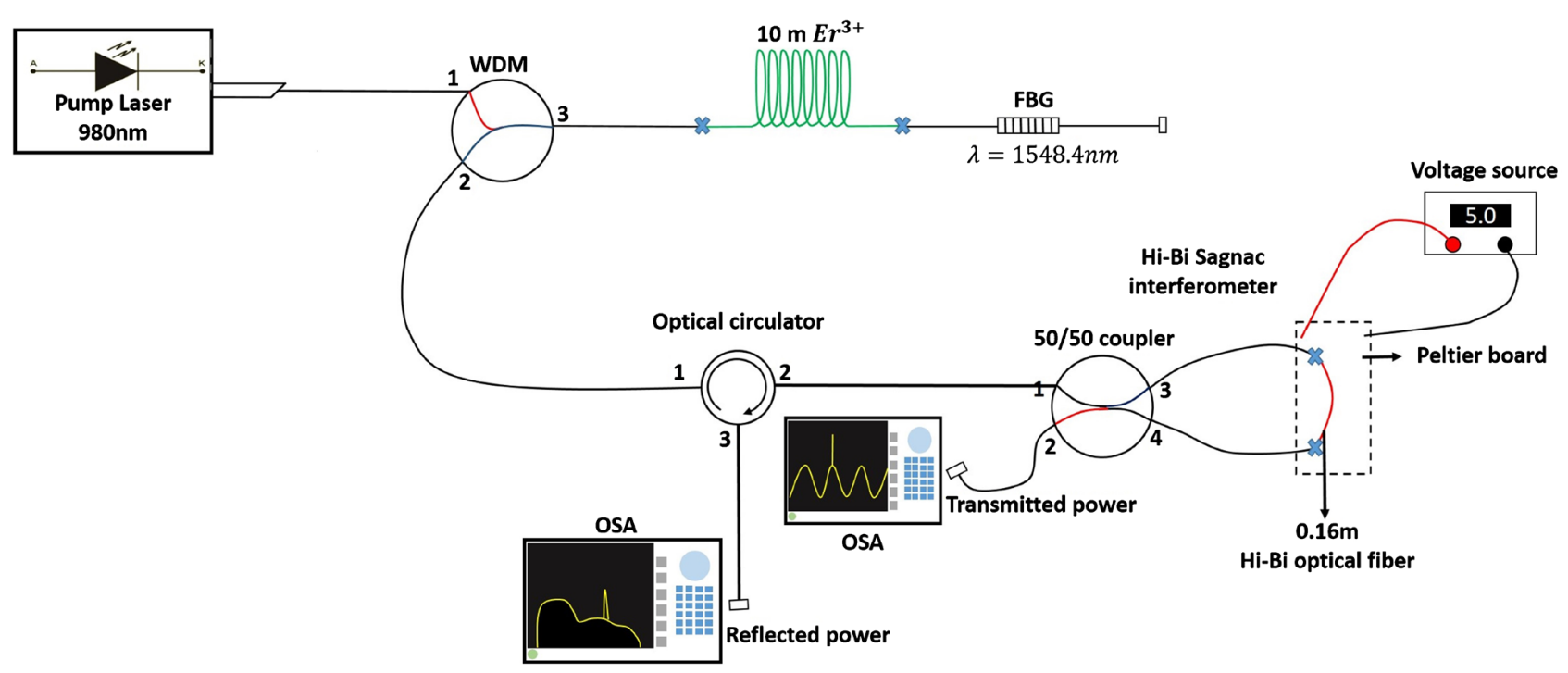

Figure 5. Optical array optimized. 
In order to do perform the remote measurement of temperature in an SI via LAN, the schematic shown in Figure 7 was employed.

First, the connectivity between the client and server inside the LAN of UNACAR is verified. If there is not connectivity, then the characterization of temperature from a remote form will not be done. In order to check the connection inside of LAN, a set of data packets were sent via internet protocol (IP) inside the LAN.

In order to secure the client-server connection and for taking the temperature measurement, the following devices were used: two computers (the first working as a client and the second as a server) the optical array called "signal amplification at $1550 \mathrm{~nm}$ and ASE noise reduction", an DS18B20 digital temperature

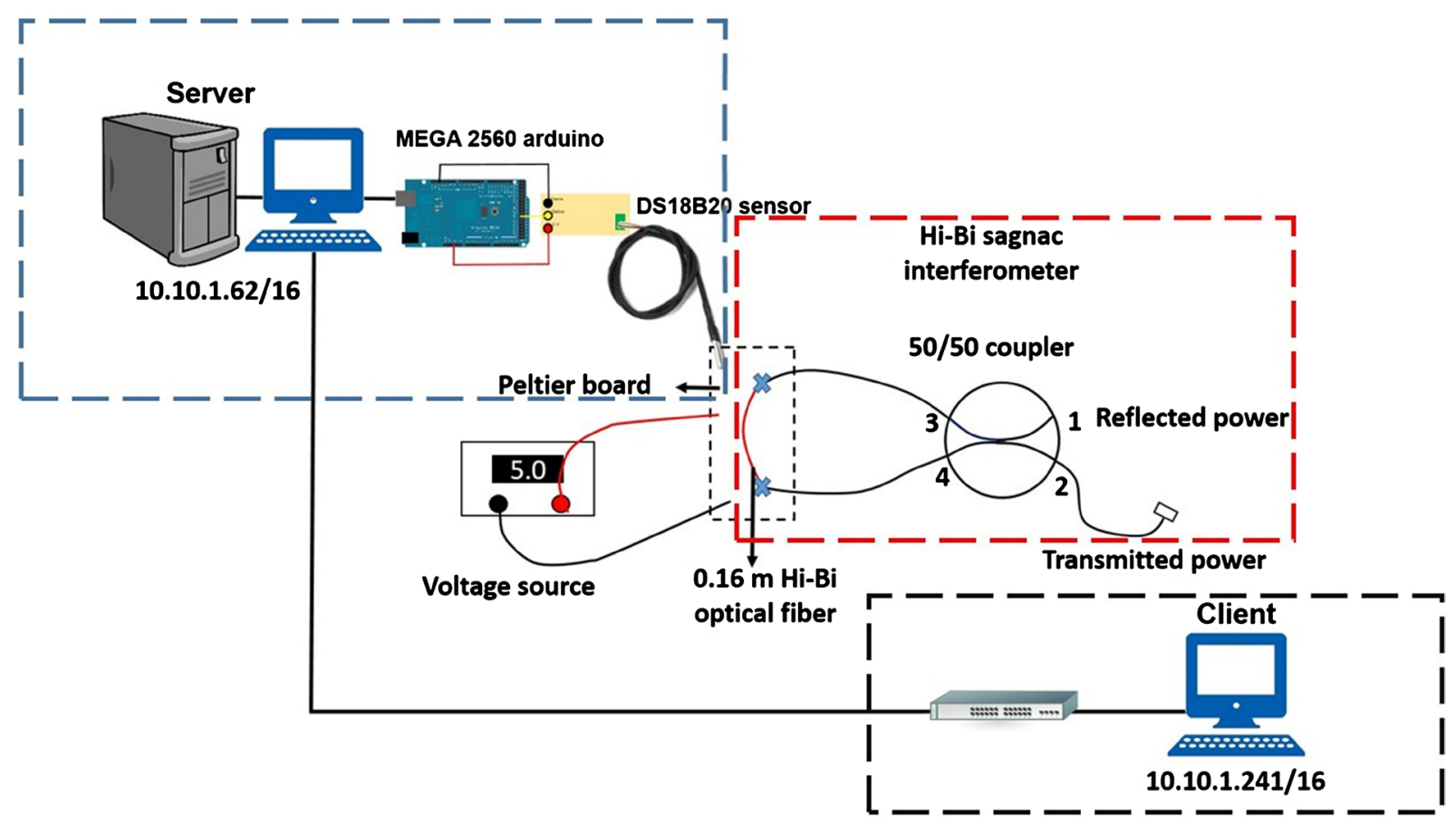

Figure 6. Schematic of remote LAN connection for temperature measurement.

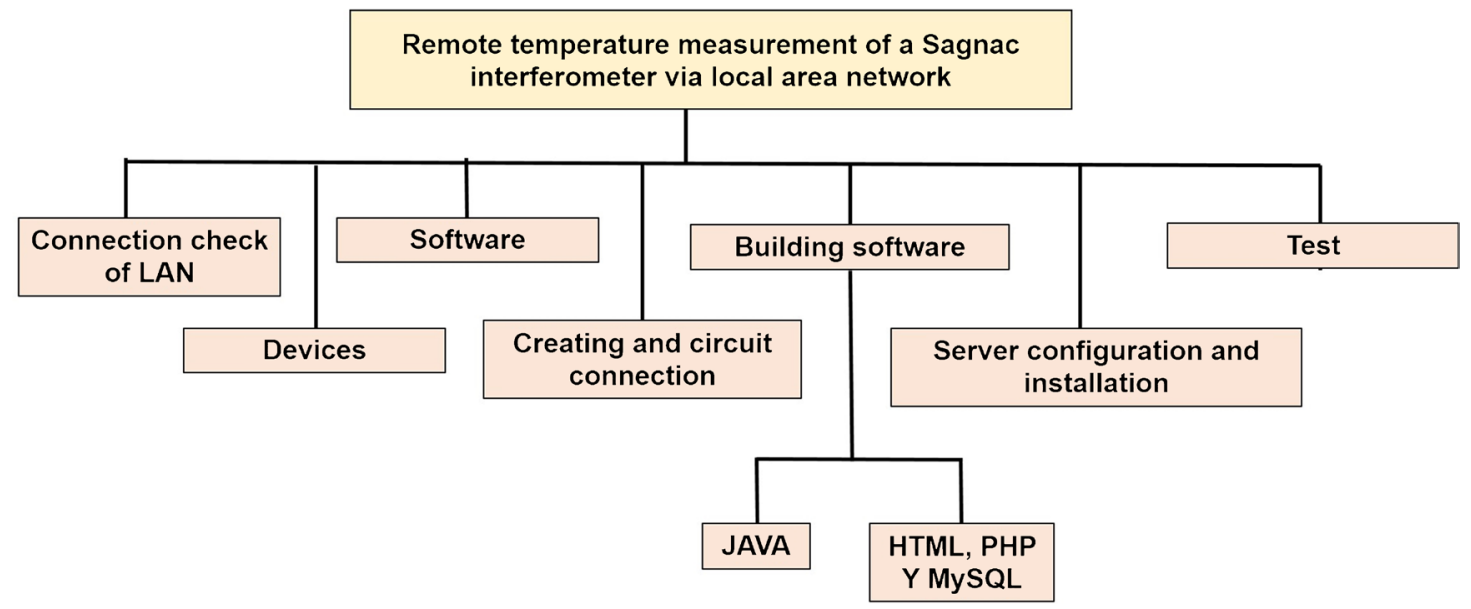

Figure 7. Remote temperature measurement of a Sagnac interferometer via local area network. 
sensor and a temperature shield to connect the temperature sensor.

The next step is to use different applications to configure the communication servers between client and server and the temperature characterization. The free software used was the following: Team Viewer for the remote connection, Xampp to up the database servers, a server of Protocol Transfer File (FTP) and apache server to visualize web pages. NetBeans IDE 8.0.2 was used to programme an app in Java. With this app the user can see the temperature characterization in a friendly screen. Sublime text 2 was also used to make or edit a web page, this was used in order to make an advanced search engine, for temperature characterization data. Arduino 1.6.5 was also employed as an interface to programme the controlled board with the temperature sensor. In order to connect the DS18B20 temperature sensor to the Arduino board, a PCB circuit had to be built for the sensor to work. The Arduino sensor shown in Figure 8, and the print circuit sensor design are explained.

In order to allow the user to characterize the temperature data, Java-based app was created. The temperature data are saved in database created for this purpose. An advanced search engine based on HTML5, PHP programming language, and MySQL database server are employed for visualization of results. Finally, LAN-based remote measurements within UNACAR campus were performed along with final tests and verification procedures.

\subsection{Print Circuit Sensor Design}

In order to perform the temperature measurement in the Hi-Bi fibre within de

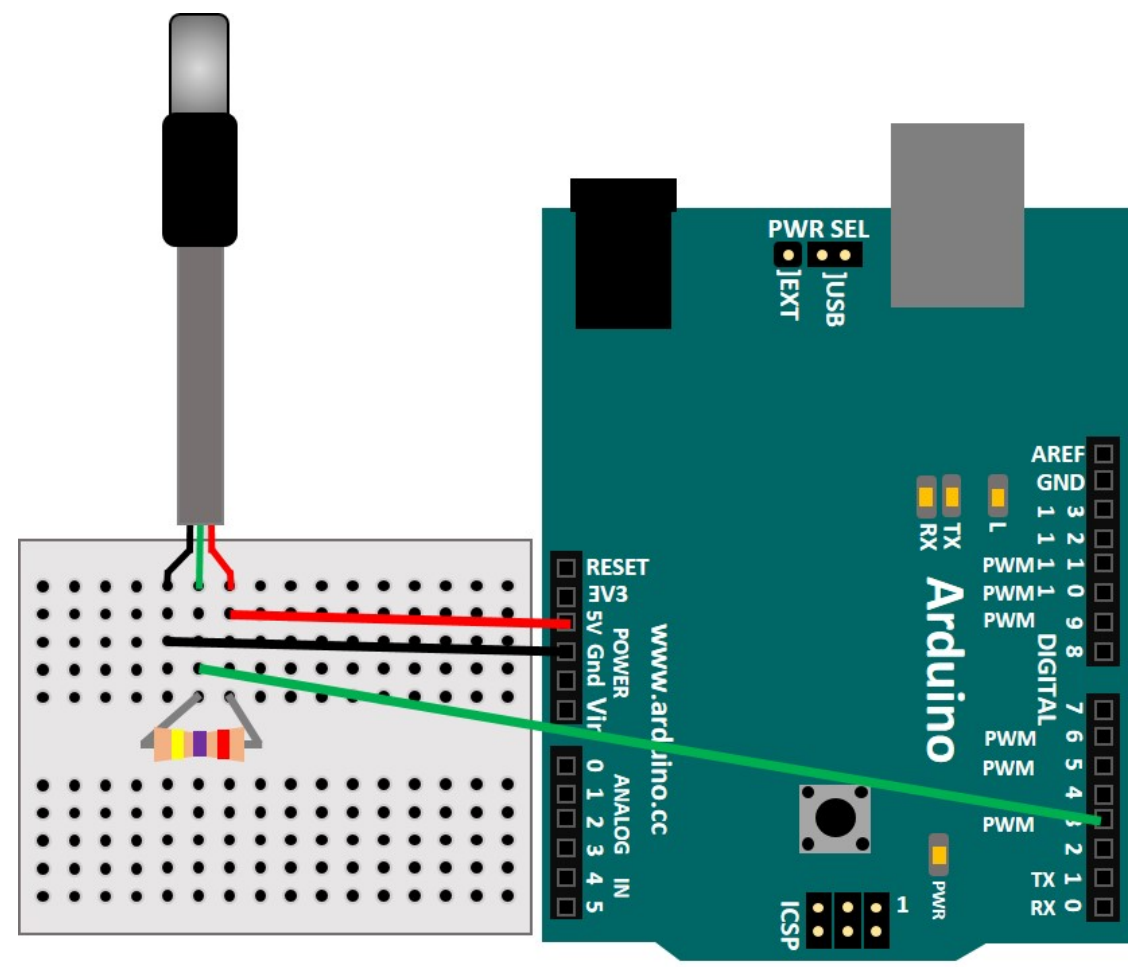

Figure 8. Arduino sensor connection. 
SI, a print circuit was made. The circuit is connected to an Arduino MEGA2560 and a DS18B20 sensor. The circuit can be connected to up to six temperature sensors, the circuit sensor connection is presented in Figure 9. Afterwards, the circuit was designed into the Printed Circuit Board (PCB). This PCB is shown in Figure 10 and Figure 11. This circuit plaque is called "Temperature Shield".

As it can be seen in Figure 9, up to 6 temperature sensors could be connected, although only 2 were employed in this experiment. The driver works as an intermediate connection between the Arduino controller and the temperature

\section{$A=5 v$ data and ground connectors}

\section{$\mathrm{SN}=$ Sensor connections}

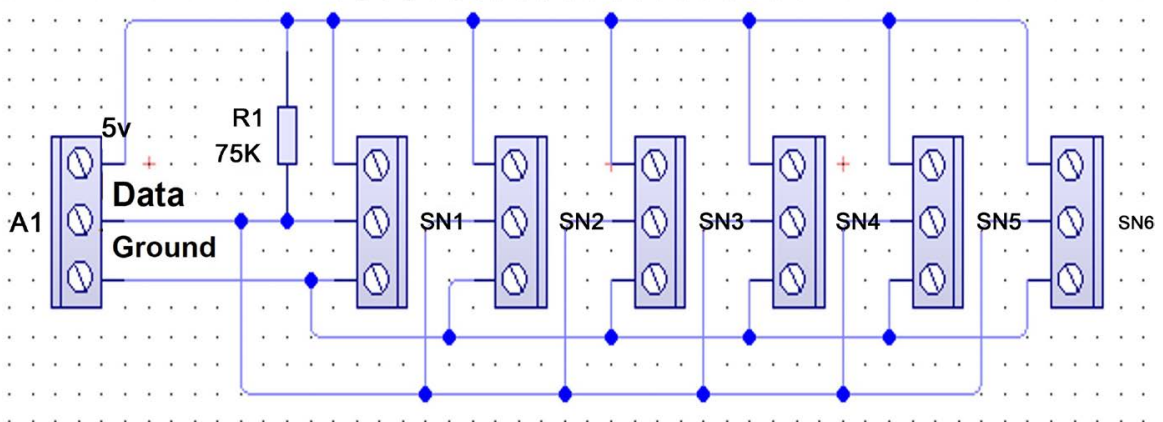

Figure 9. Electronic circuit for connect the DS18B20 temperature sensor to Arduino MEGA2560.

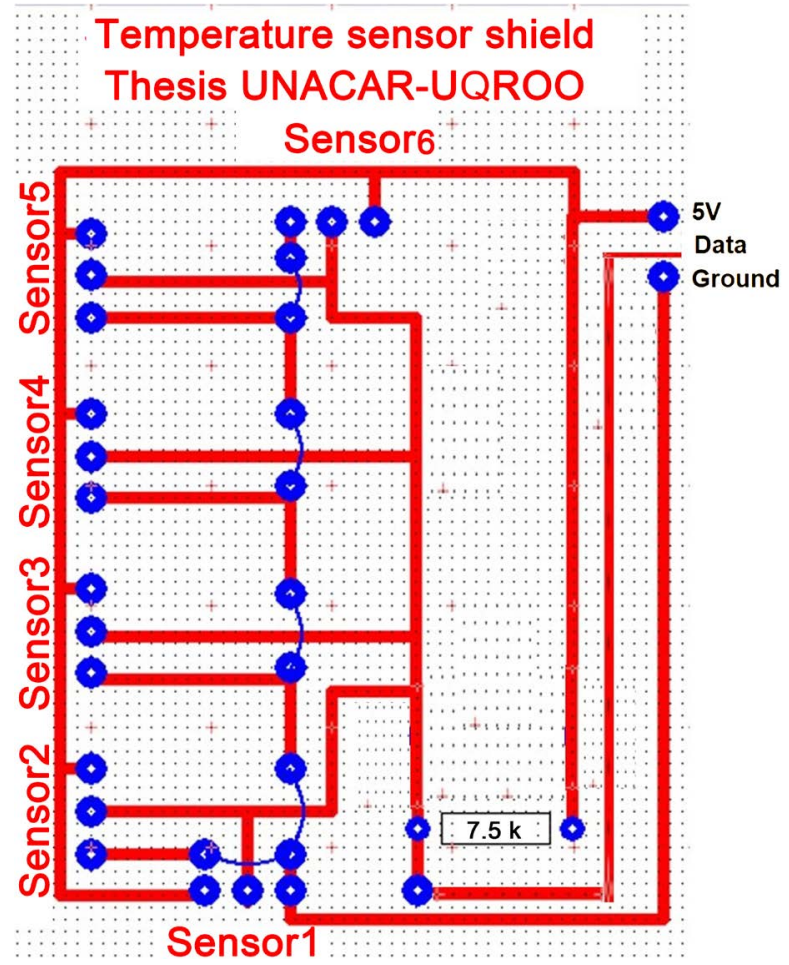

Figure 10. Template for the circuit electronic in PCB. 
sensors. The PCB is shown in Figure 10 below, on which the sensors are connected under the labels "sensor 1" and "sensor 2".

An example of the temperature measurement in the Arduino display using the temperature shield and sensors are shown in the result section.

\section{Results}

In brief, our results include: 1) EDFA ASE noise at the reflected power measurement, 2) Optical circulator spectral characterization via ASE noise measurement at the reflected power, 3) Sagnac interferometer + optical circulator spectral characterization (with $0.22 \mathrm{~m}$ of $\mathrm{Hi}-\mathrm{Bi}$ fibre at $27^{\circ} \mathrm{C}$ ) at both reflected and transmitted power, 4) Sagnac interferometer + optical circulator spectral characterization (with $\mathrm{Hi}-\mathrm{Bi}$ fibre at $27^{\circ} \mathrm{C}, 30^{\circ} \mathrm{C}, 47^{\circ} \mathrm{C}, 87^{\circ} \mathrm{C}, 103^{\circ} \mathrm{C}$ and $104^{\circ} \mathrm{C}$ ) at both reflected and transmitted power, 5) General programming and electronics design for the sensors and Arduino microcontroller and finally, 6) Local area network characterization.

Figure 13 and Figure 14 show the ASE noise and power spectrum characterization with and optical circulator added to the EDFA. It should be noted that it is possible to obtain higher power transmission from $10 \mathrm{~mA}$ to $200 \mathrm{~mA}$ at port number 2. Also, the power reflection was lower, thus reducing the loss of power due to reflection in the optical array.

The general optical array is shown in Figure 15 and Figure 16. Figure 15 shows the characterization of the optical array with the transmitted signal at a minimum power of $-35.62 \mathrm{dBm}$, a minimum power of $27.4 \mu \mathrm{W}$ and a pump power of $30 \mathrm{~mA}$, also at a maximum power of $1.93 \mathrm{dBm}$, a maximum power of $1.56 \mathrm{~mW}$ and a pump power of $200 \mathrm{~mA}$.

As it can be seen in Figure 14, very low power is reflected from port 2 of the

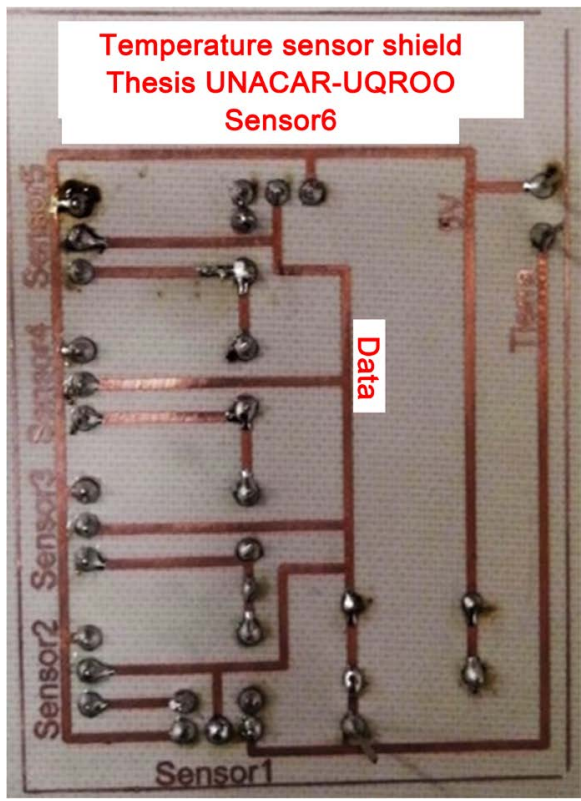

Figure 11. PCB of the temperature shield. 


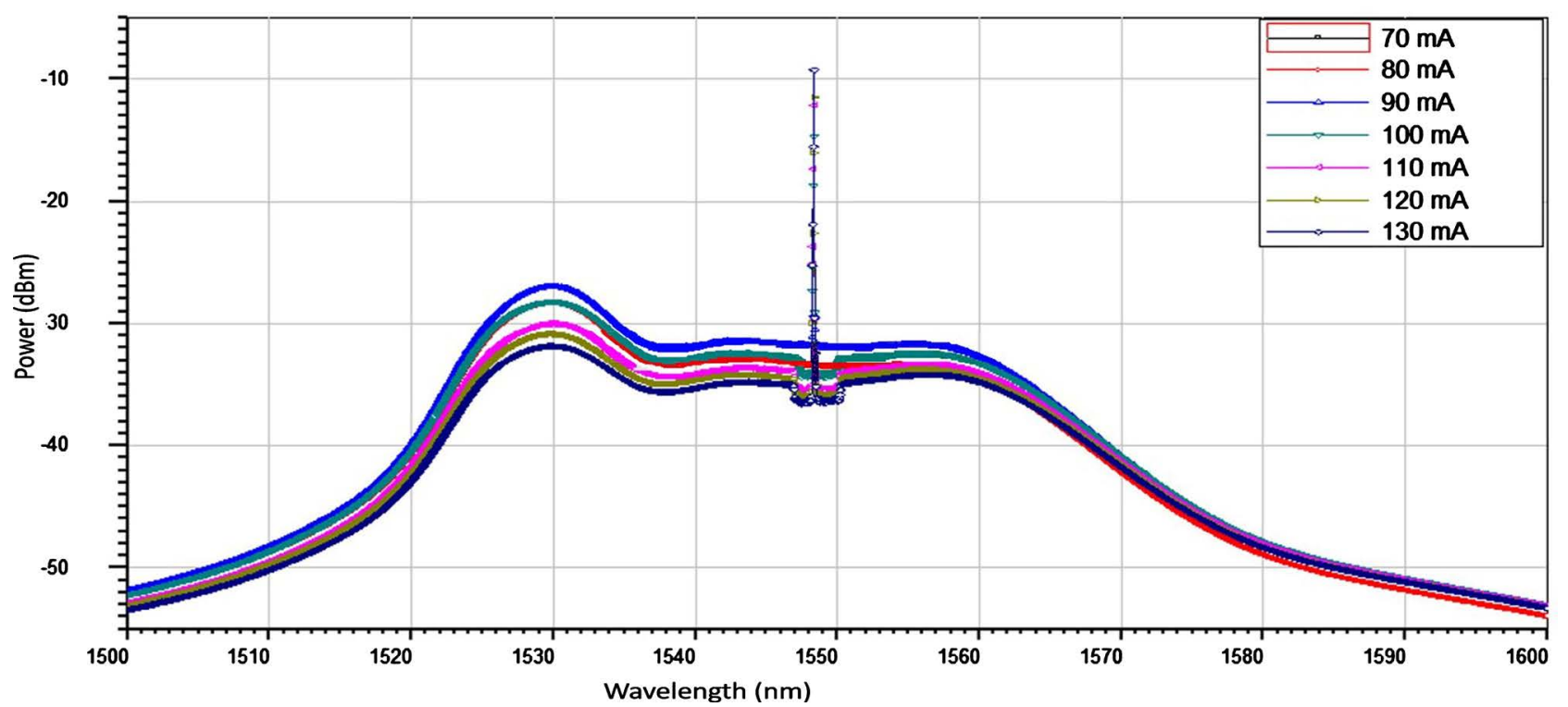

Figure 12. Characterization of ASE noise.

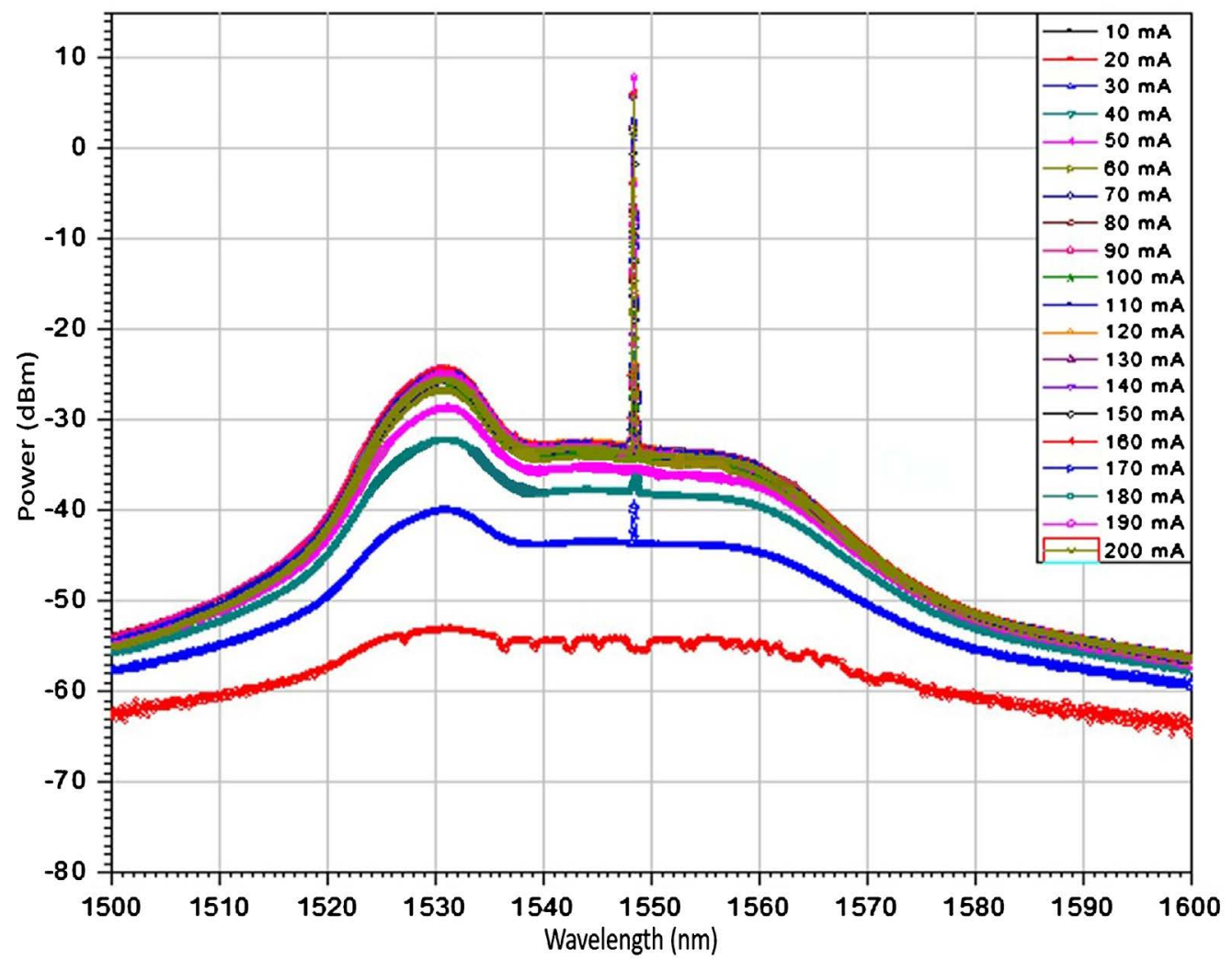

Figure 13. Characterization of ASE noise with an optical circulator in the port number 2.

circulator. Furthermore, an attenuation of approximately $27 \mathrm{~dB}$ is found at both 1530 and $1548.4 \mathrm{~nm}$ when comparing Figure 13 and Figure 14.

Figure 16 shows the characterized reflection power of the general optical array with a minimum power of $-30.61 \mathrm{dBm}$, a minimum power of $86.89 \mu \mathrm{W}$ and a pump power of $30 \mathrm{~mA}$, also a maximum power of $6.14 \mathrm{dBm}$, a maximum 


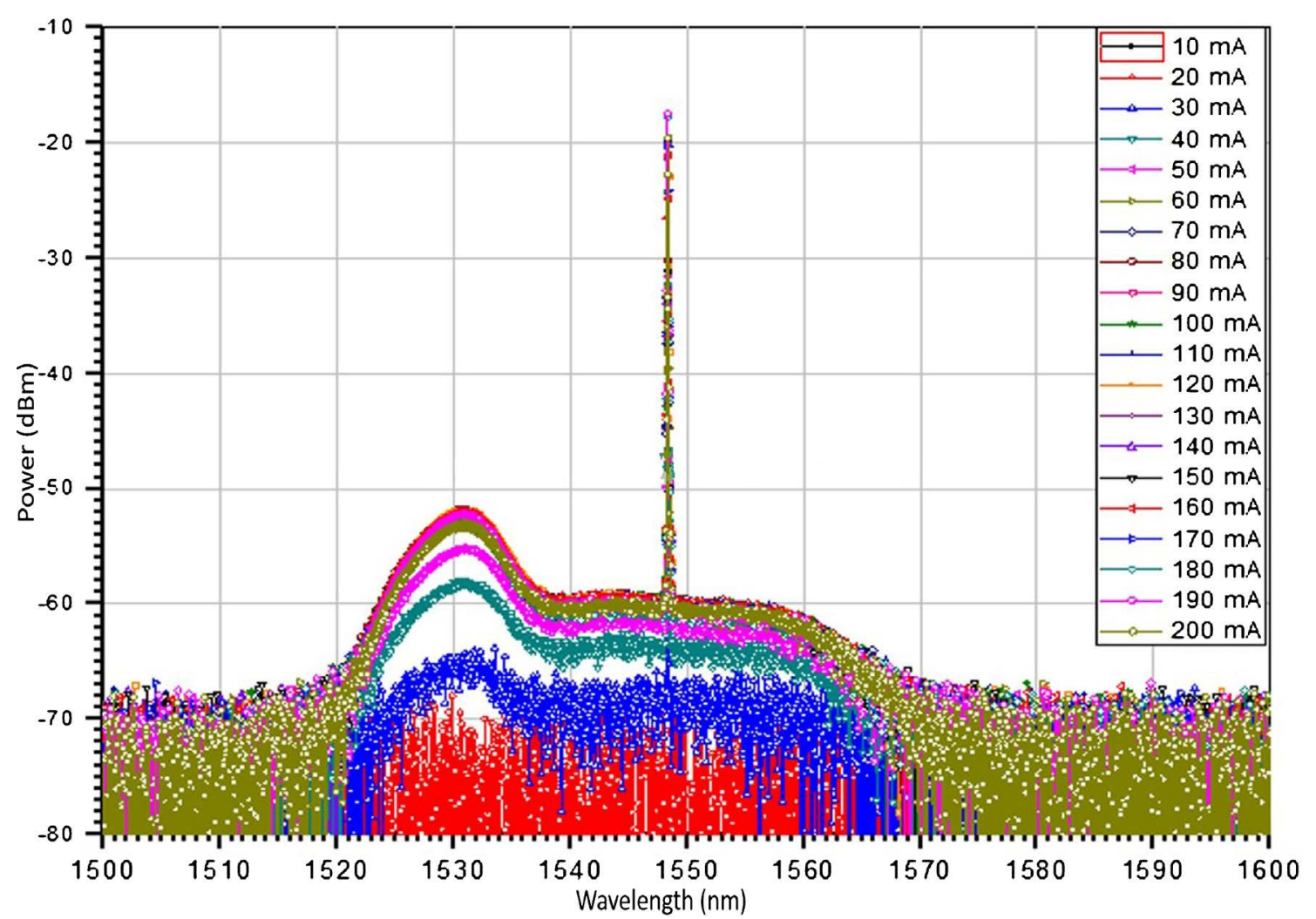

Figure 14. Characterization of ASE noise with an optical circulator in the port number 3.

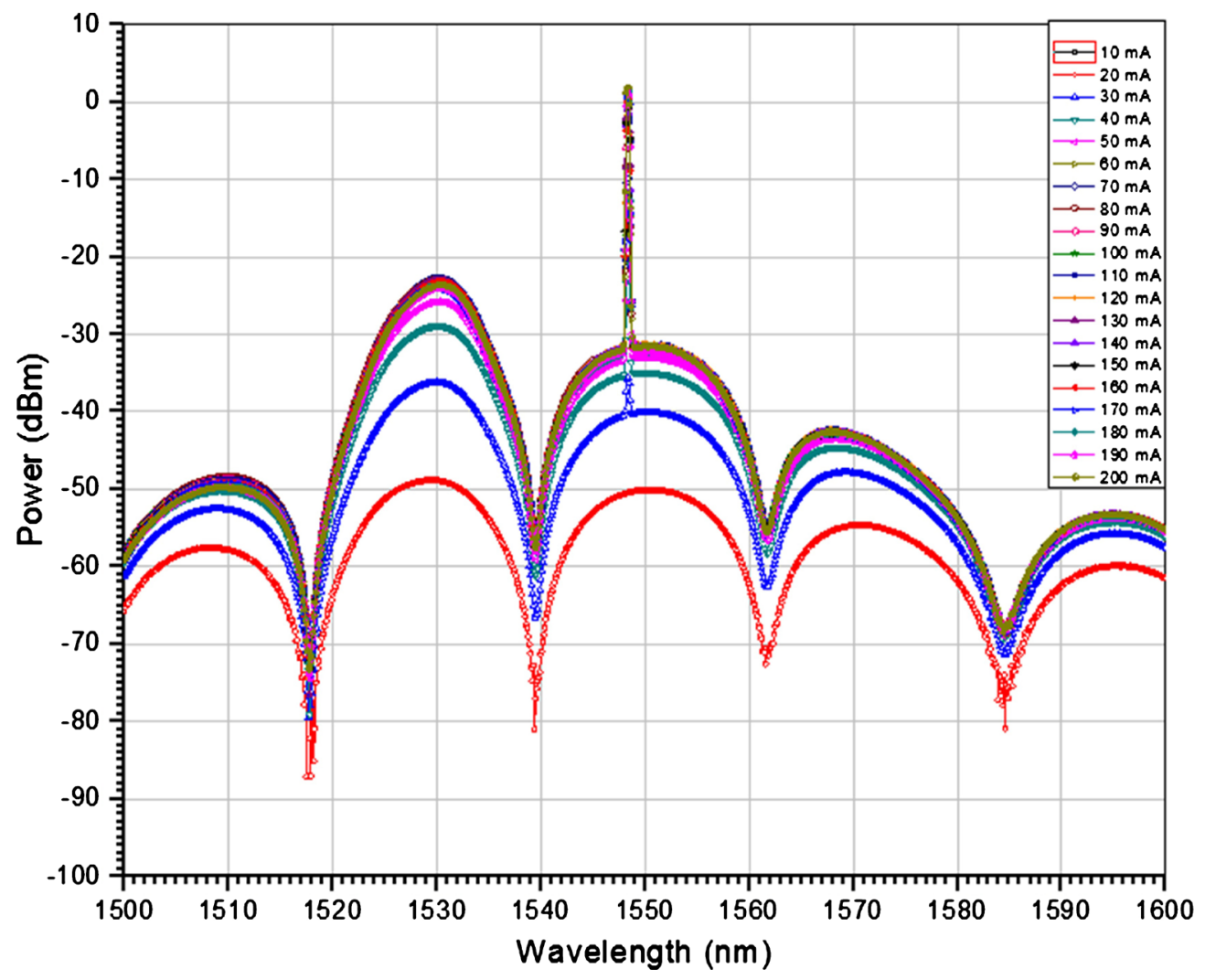

Figure 15. Spectrum of transmitted power. 


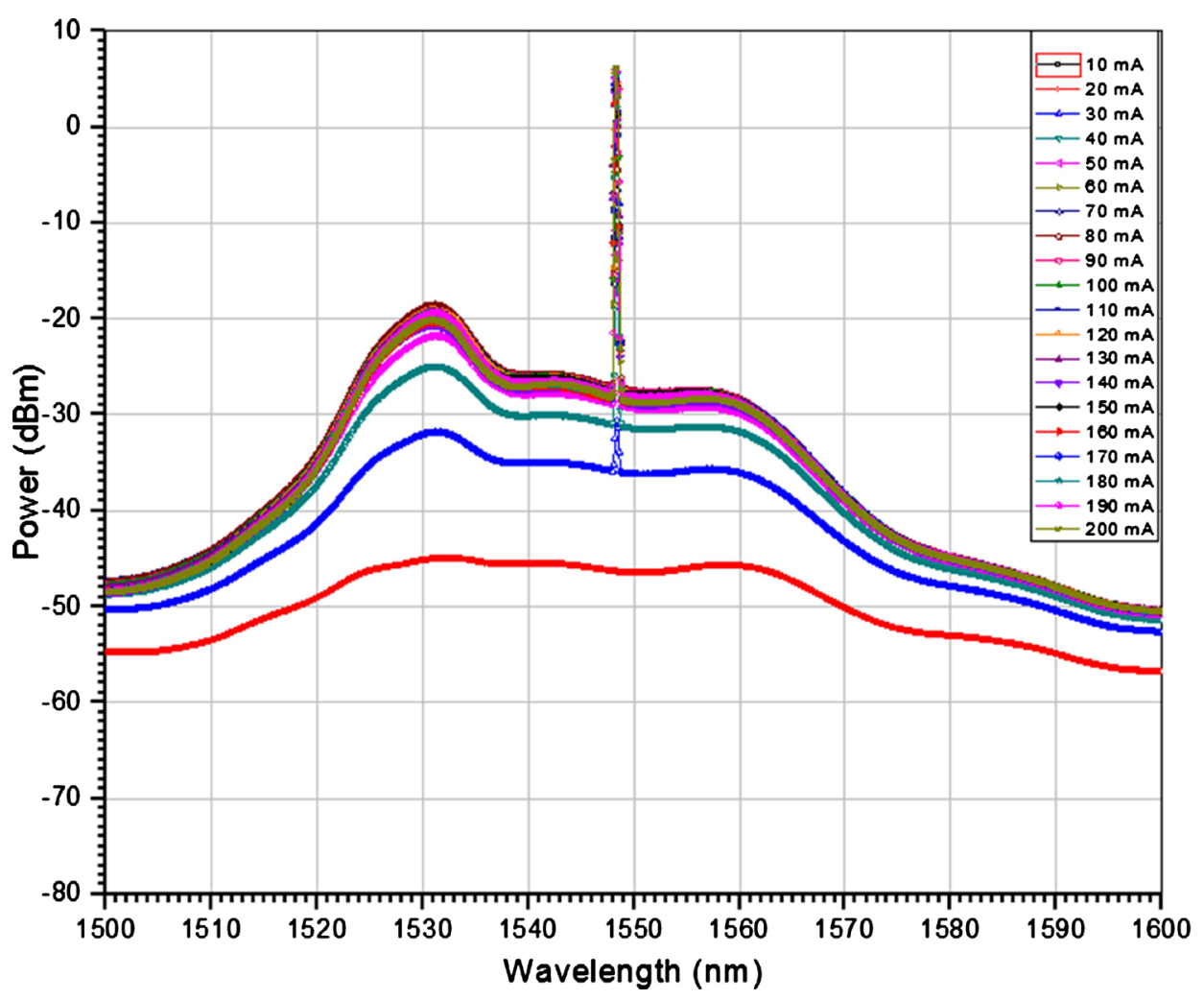

Figure 16. Spectrum of reflected power.

power of $4.11149 \mathrm{~mW}$ and a pump power of $200 \mathrm{~mA}$. A comparison of Figure 15 and Figure 16 are compared, the reflection power is higher than the transmitted power.

We will now show the results of the optical array after it was characterized and after the temperature was applied. Such characterization was made in the output port two of the transmitted power of SI at room temperature, with power ranges from $70 \mathrm{~mA}$ to $100 \mathrm{~mA}$ and with a voltage from $1 \mathrm{~V}$ to $10 \mathrm{~V}$. Also, the characterization is made at the output port three of the optical circulator for characterizing the reflected power at room temperature and with same power and voltage ranges.

By comparing Figure 15 and Figure 16, one can note that the IS reflected power in Figure 16, does not show the noticeable valleys of Figure 15.

In Figures 17-19 the characterization shows the transmitted power in the output port number two of the SI.

Figure 17 shows that for a shorter Hi-Bi fiber a wider separation in between valleys is obtained from the spectral characterization (see Equation (1)). Therefore, there are fewer valleys in the range between 1500 and $1600 \mathrm{~nm}$, in comparison with Figure 15. It can also be observed that the maximum transmitted power is reached around $1548.4 \mathrm{~nm}$ with an observed minimum power value at $1530 \mathrm{~nm}$, where the ASE noise level is maximum.

The highest power in the system was obtained with a pump power of $100 \mathrm{~mA}$ and $8 \mathrm{~V}$ at $87.4^{\circ} \mathrm{C}$, as it is shown in Figure 20. 
Figures 18-20 show a fine tuning process of the main optical array via heating of the Hi-Bi fibre. After heating the fibre, the valleys shift towards shorter wavelengths, by which one could tune maximum and minimum transmitted power levels, in order to lower the ASE noise level in the whole set up.

In Figures 21-23 the characterization was made in the output port number three of the reflection power of optical circulator with a temperature of $27^{\circ} \mathrm{C}$ and adding current from $70 \mathrm{~mA}$ to $100 \mathrm{~mA}$ and with a voltage of $1 \mathrm{~V}$ to $10 \mathrm{~V}$.

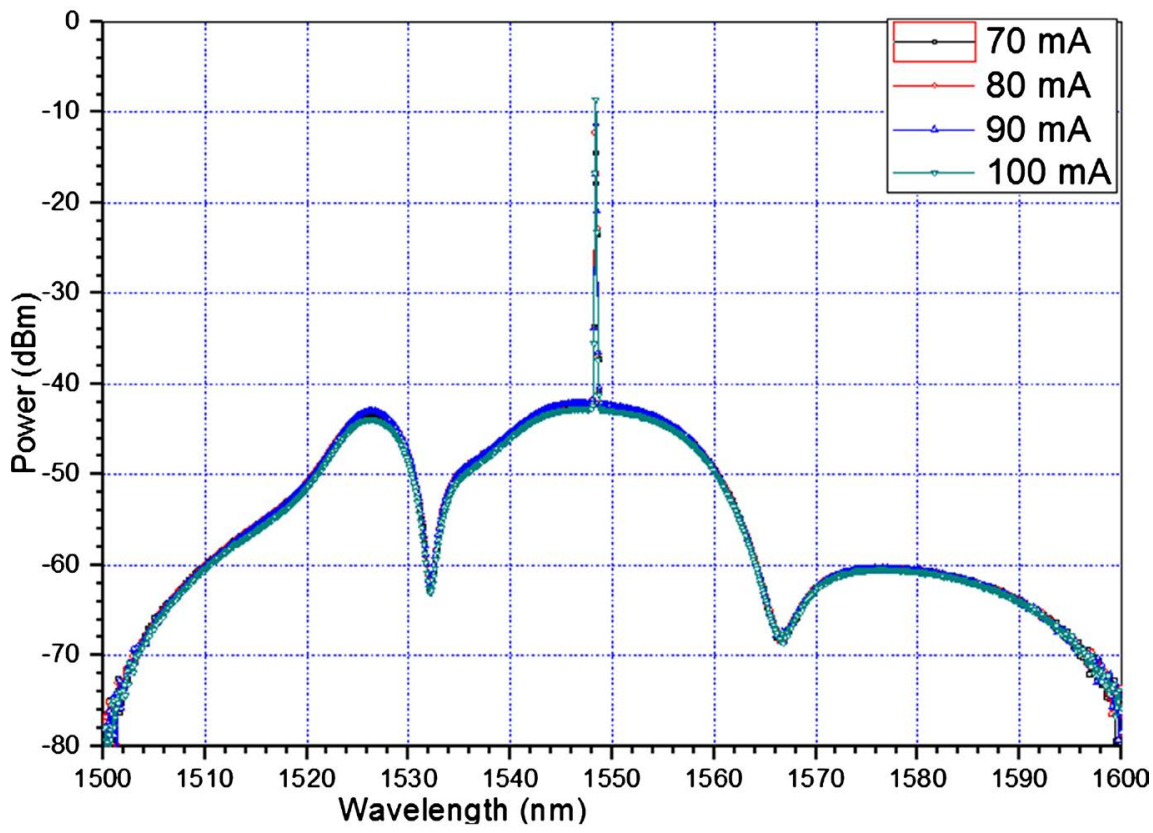

Figure 17. Spectrum of transmitted power at $27^{\circ} \mathrm{C}$ temperature.

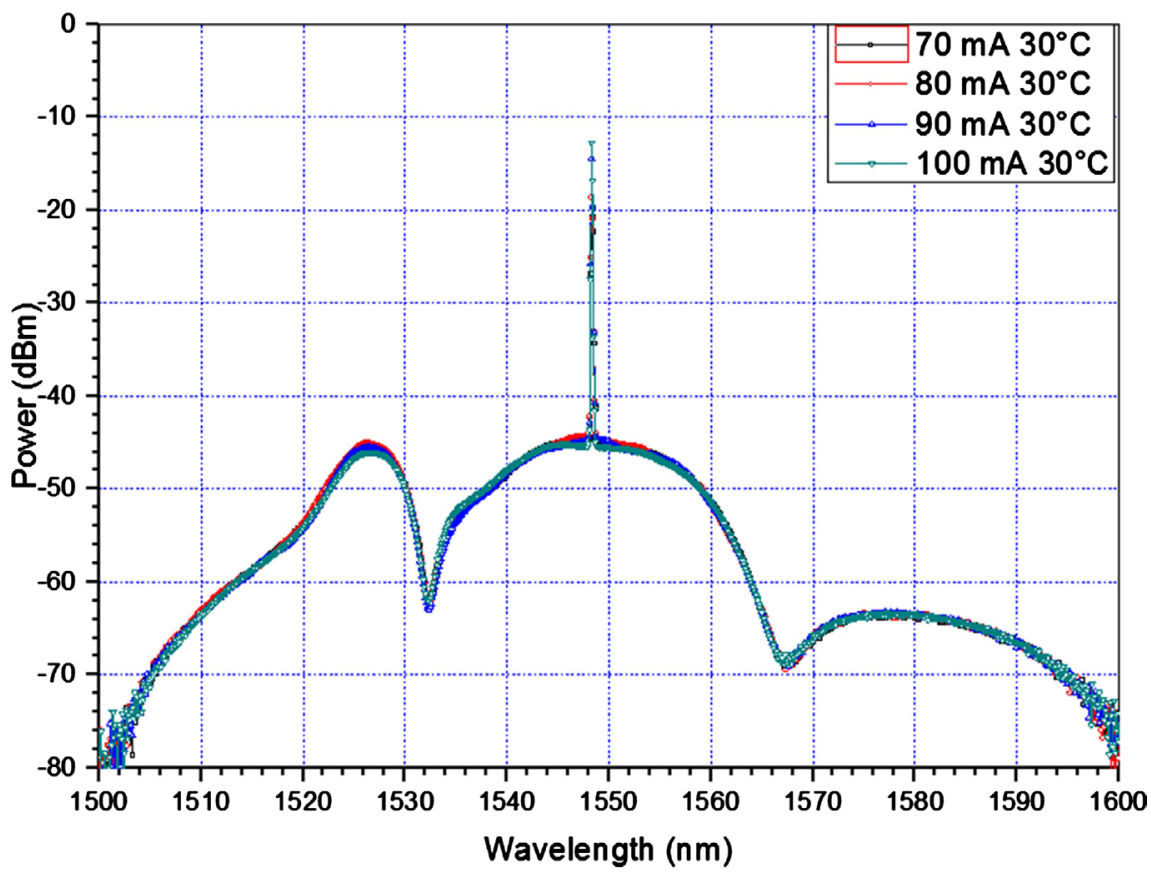

Figure 18. Spectrum of transmitted power with $0.16 \mathrm{~m}$ of $\mathrm{Hi}-\mathrm{Bi}$ fiber. 


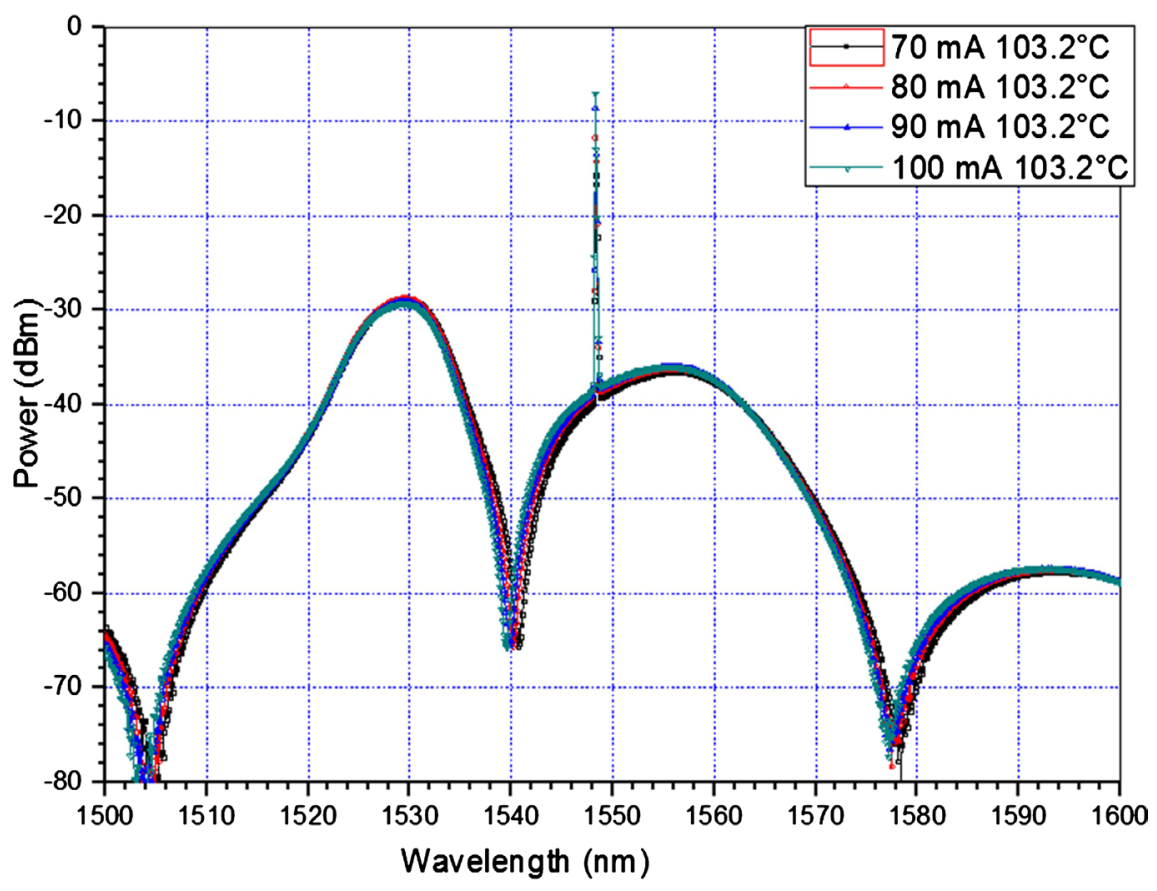

Figure 19. Spectrum of transmitted power with $0.16 \mathrm{~m}$ of $\mathrm{Hi}-\mathrm{Bi}$ fiber.

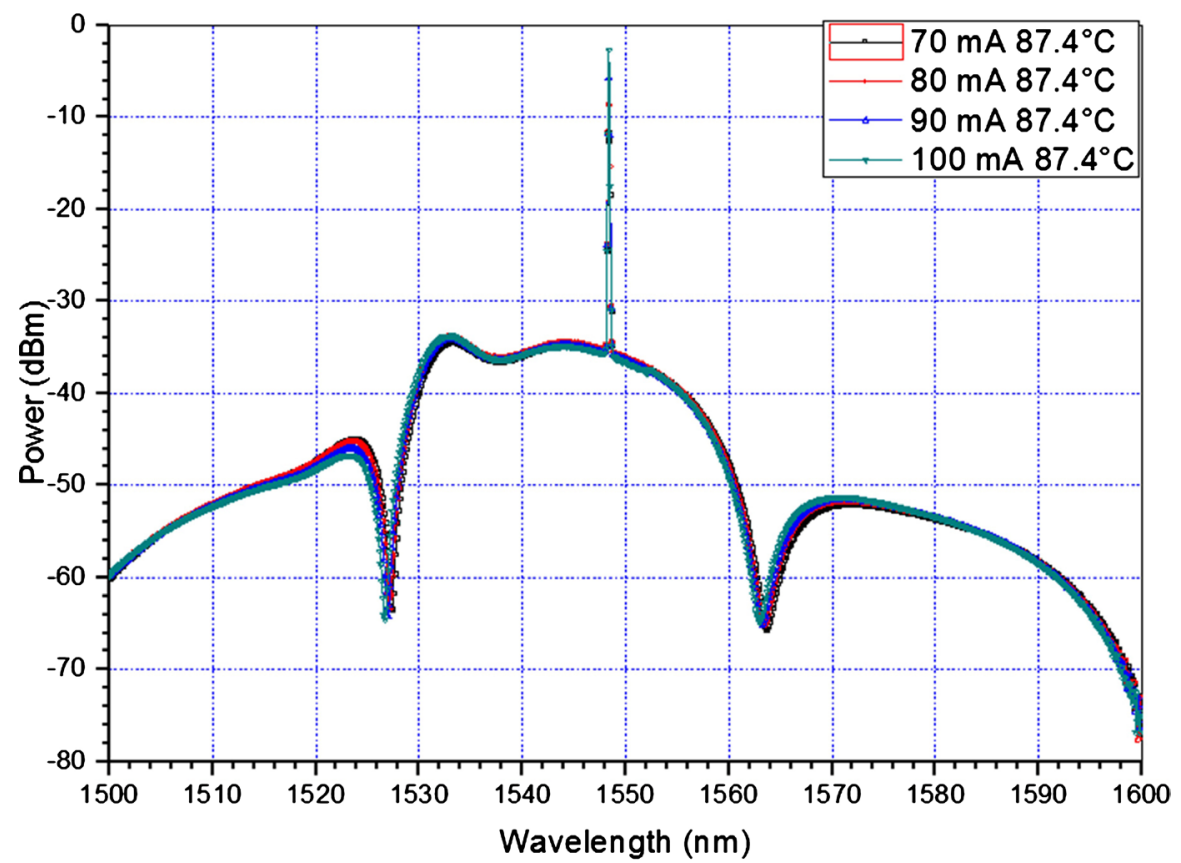

Figure 20. Spectrum of the maximum transmitted power with $0.16 \mathrm{~m}$ of $\mathrm{Hi}-\mathrm{Bi}$ fiber.

Figures 21-23 show the reflected SI power measured at port 3 of the optical circulator. Such figures are similar to Figure 13 although a higher (by $10 \mathrm{~dB}$ ) attenuation is observed, particularly for wavelengths around 1550 as shown in Figure 20.

The highest power when the $\mathrm{Hi}-\mathrm{Bi}$ fibre is at its highest temperature was measured after $100 \mathrm{~mA}$ of pump power at $47.4^{\circ} \mathrm{C}$, as shown in Figure 24 . 


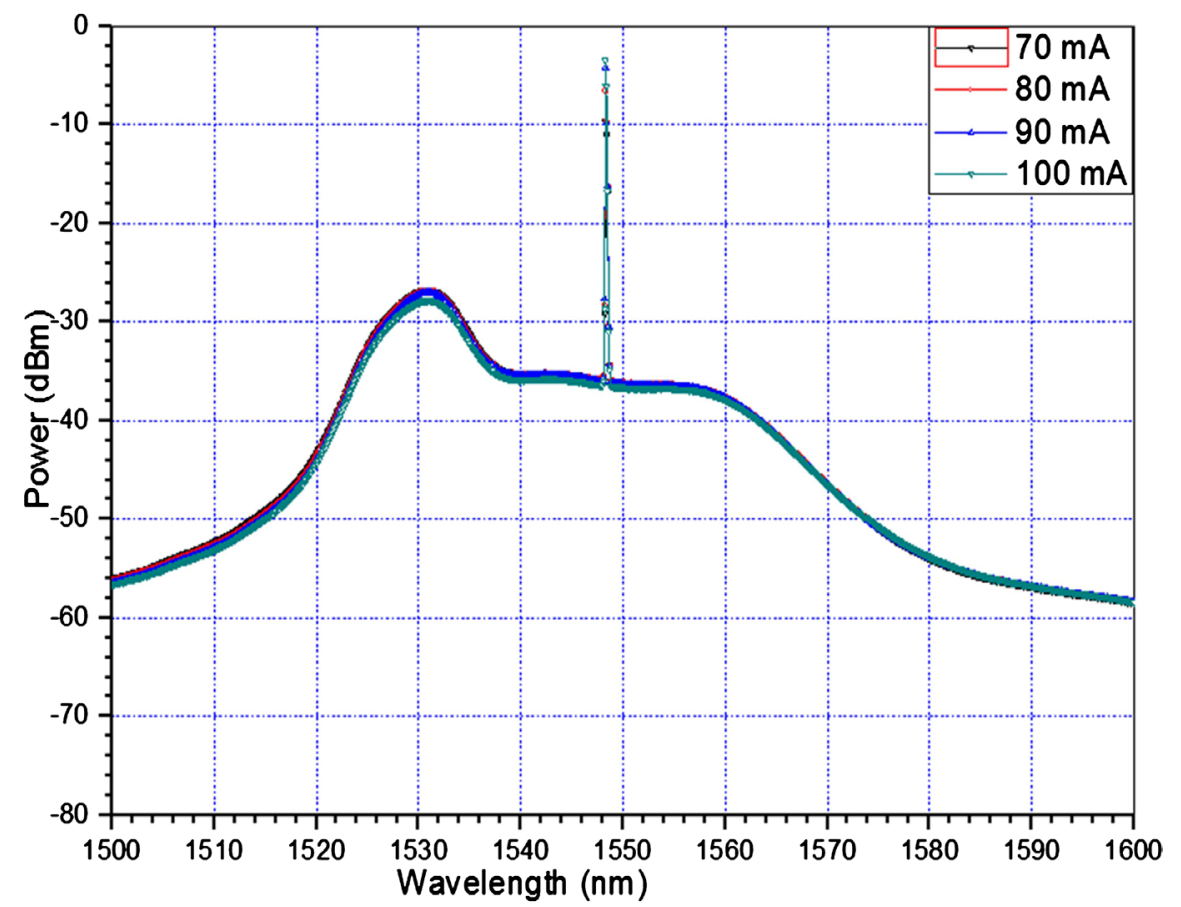

Figure 21. Spectrum of reflected power of the circulator in the port output three with a room temperature at $27^{\circ} \mathrm{C}$.

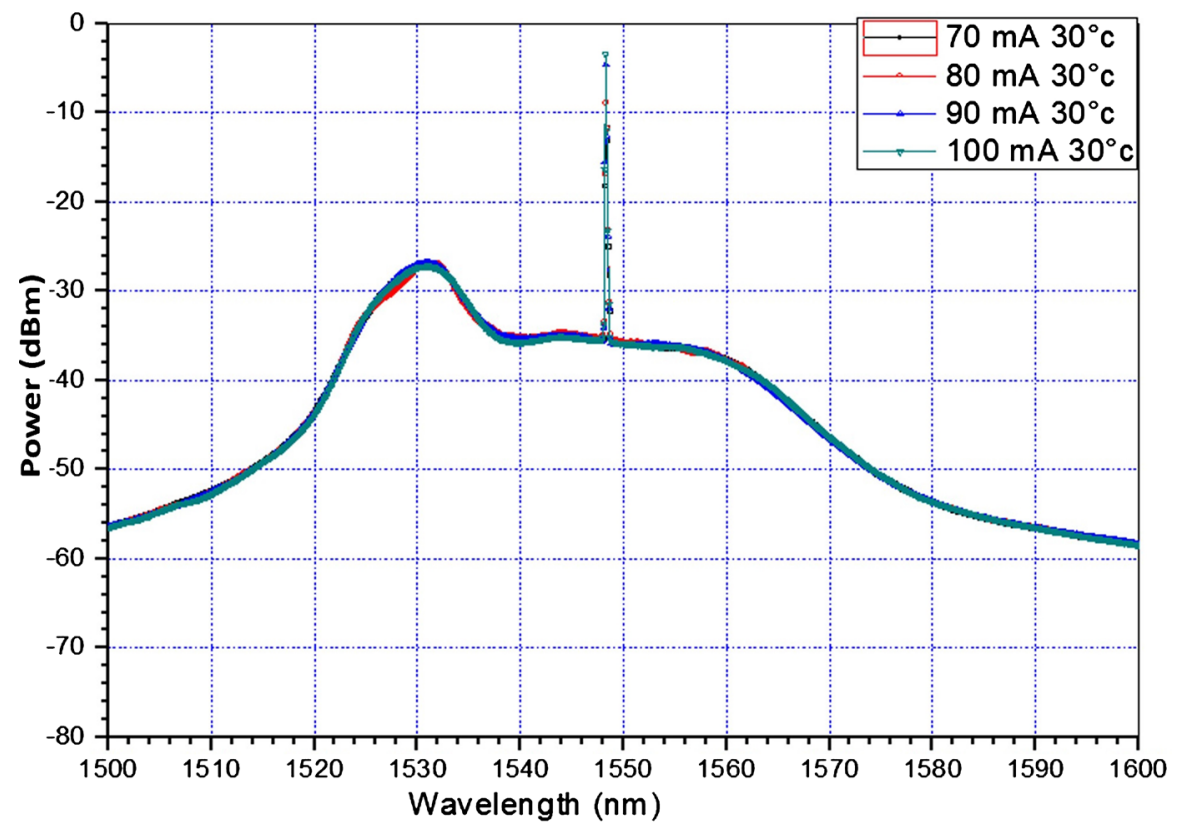

Figure 22. Spectrum of reflection power of the circulator in the port output three for $1 \mathrm{~V}$ and $30^{\circ} \mathrm{C}$.

In this section the temperature shield is shown. It was connected to the Arduino MEGA2560 and the DS18B20 temperature sensor. Afterwards, the Arduino MEGA2560 microcontroller was programmed to characterize the temperature in the Hi-Bi fibre. Figure 25 shows an example of the temperature measurement in the Arduino display. 


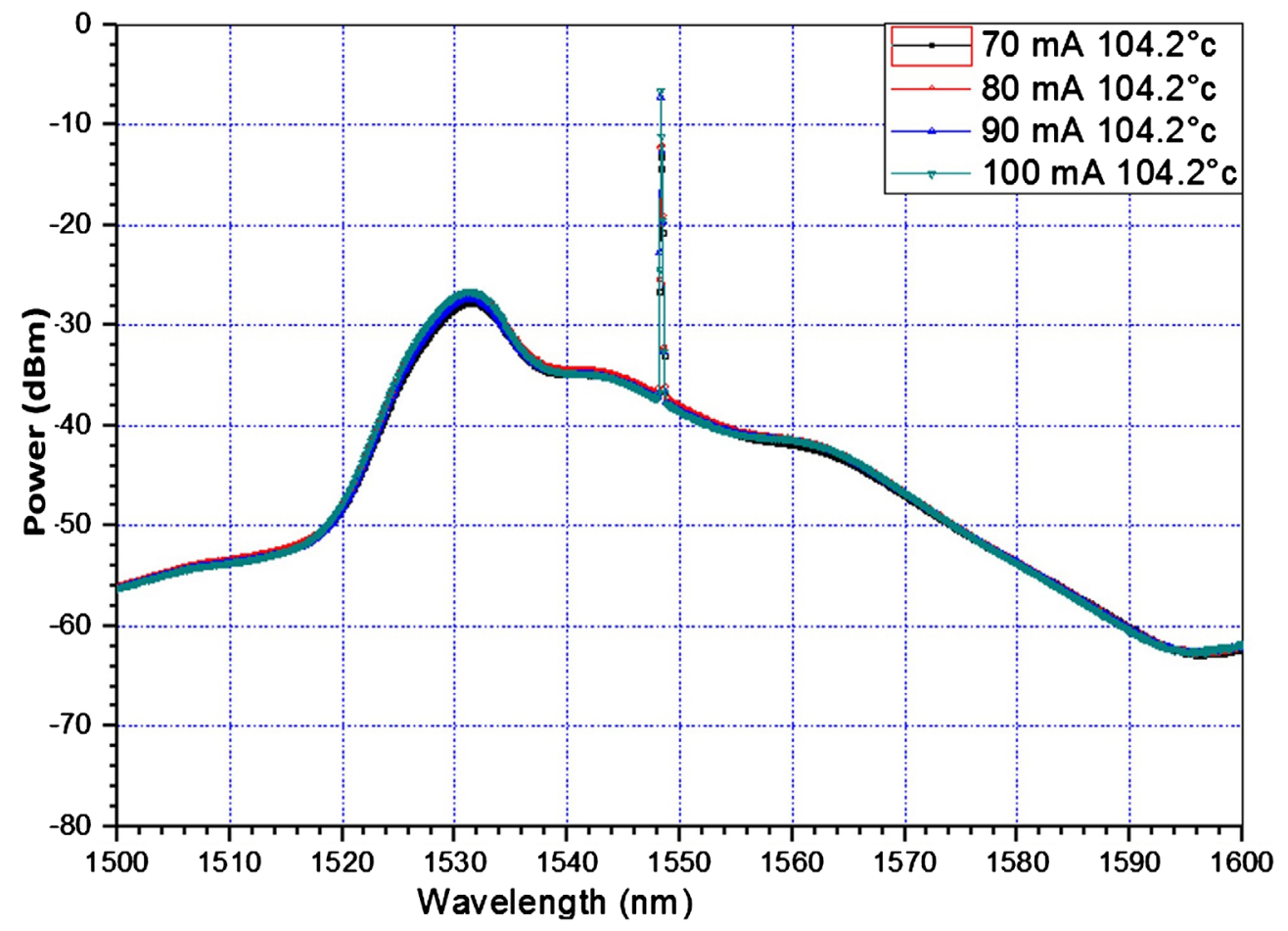

Figure 23. Spectrum of reflected power of the circulator at output port three.

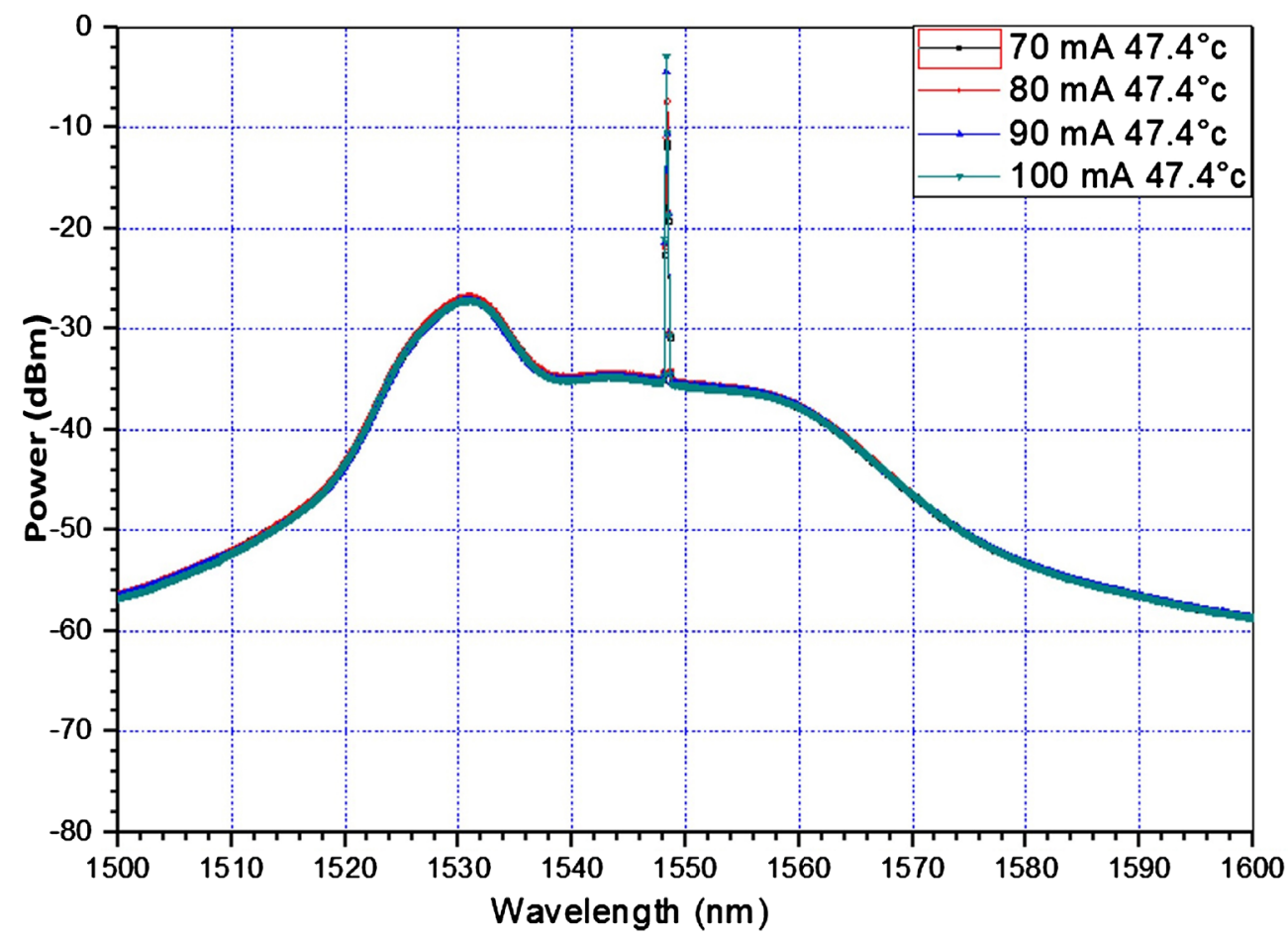

Figure 24. Spectrum of the maximum reflected power at output port three for $-47.4^{\circ} \mathrm{C}$. 


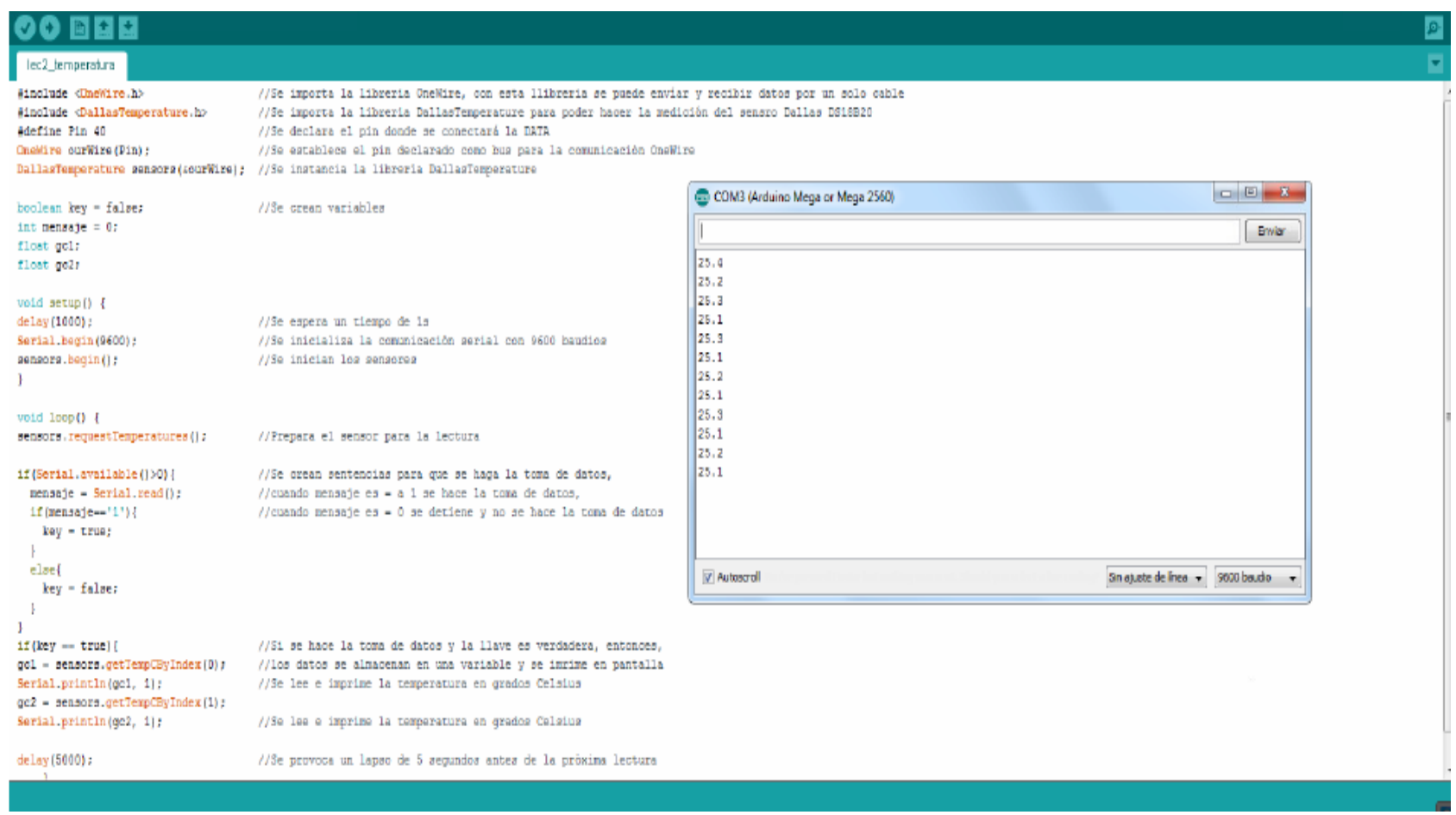

Figure 25. DS18B20 sensor data programmed in Arduino.

\section{Arduino code for 2 sensors}

\#include < OneWire.h>

\#include $<$ DallasTemperature.h $>$

\#define Pin 40

OneWire ourWire(Pin);

DallasTemperature sensors(\&ourWire);

boolean key = false;

int mensaje $=0$;

float gc1;

float gc2;

void $\operatorname{setup}()\{$

delay(1000);

Serial.begin(9600);

sensors.begin();

\}

void $\operatorname{loop}()\{$

sensors.requestTemperatures();

if(Serial.available ()$>0)\{$

mensaje $=$ Serial.read () ;
// OneWire library is imported

//DallasTemperature library is imported for using the DS18B20

//Pin 40 is defined

//Se establece el pin declarado como bus para la comunicación OneWire //Se instancia la librería DallasTemperature

//Se crean variables

//Se espera un tiempo de un segundo

//Se inicializa la comunicación serial con 9600 baudios

//Se inician los sensores

//Prepara el sensor para la lectura

//Se crean sentencias para que se haga la toma de datos, //cuando mensaje es = a uno se hace la toma de datos, 


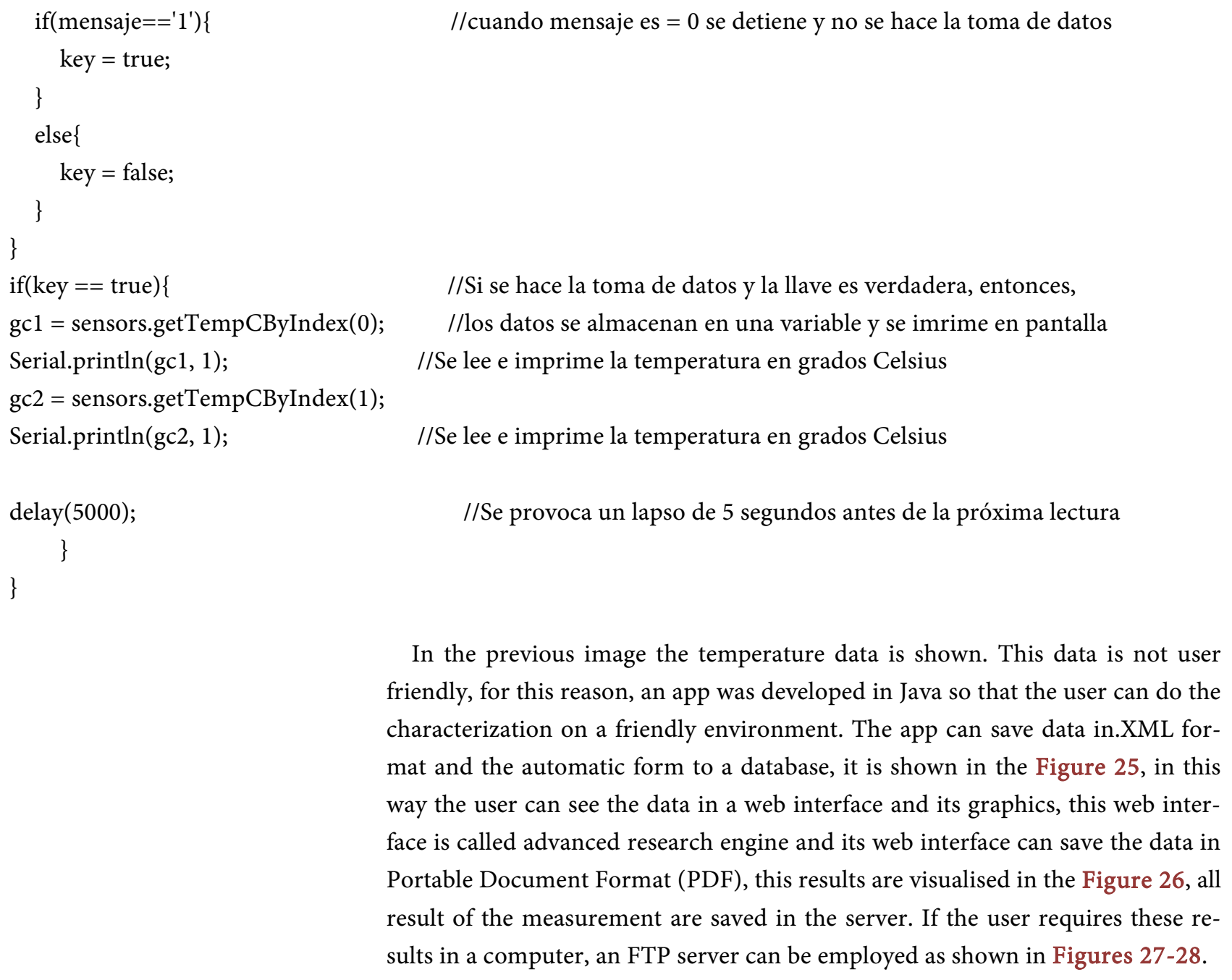

//Si se hace la toma de datos y la llave es verdadera, entonces, //los datos se almacenan en una variable y se imrime en pantalla //Se lee e imprime la temperatura en grados Celsius

//Se lee e imprime la temperatura en grados Celsius

//Se provoca un lapso de 5 segundos antes de la próxima lectura

In the previous image the temperature data is shown. This data is not user friendly, for this reason, an app was developed in Java so that the user can do the characterization on a friendly environment. The app can save data in.XML format and the automatic form to a database, it is shown in the Figure 25, in this way the user can see the data in a web interface and its graphics, this web interface is called advanced research engine and its web interface can save the data in Portable Document Format (PDF), this results are visualised in the Figure 26, all result of the measurement are saved in the server. If the user requires these results in a computer, an FTP server can be employed as shown in Figures 27-28.

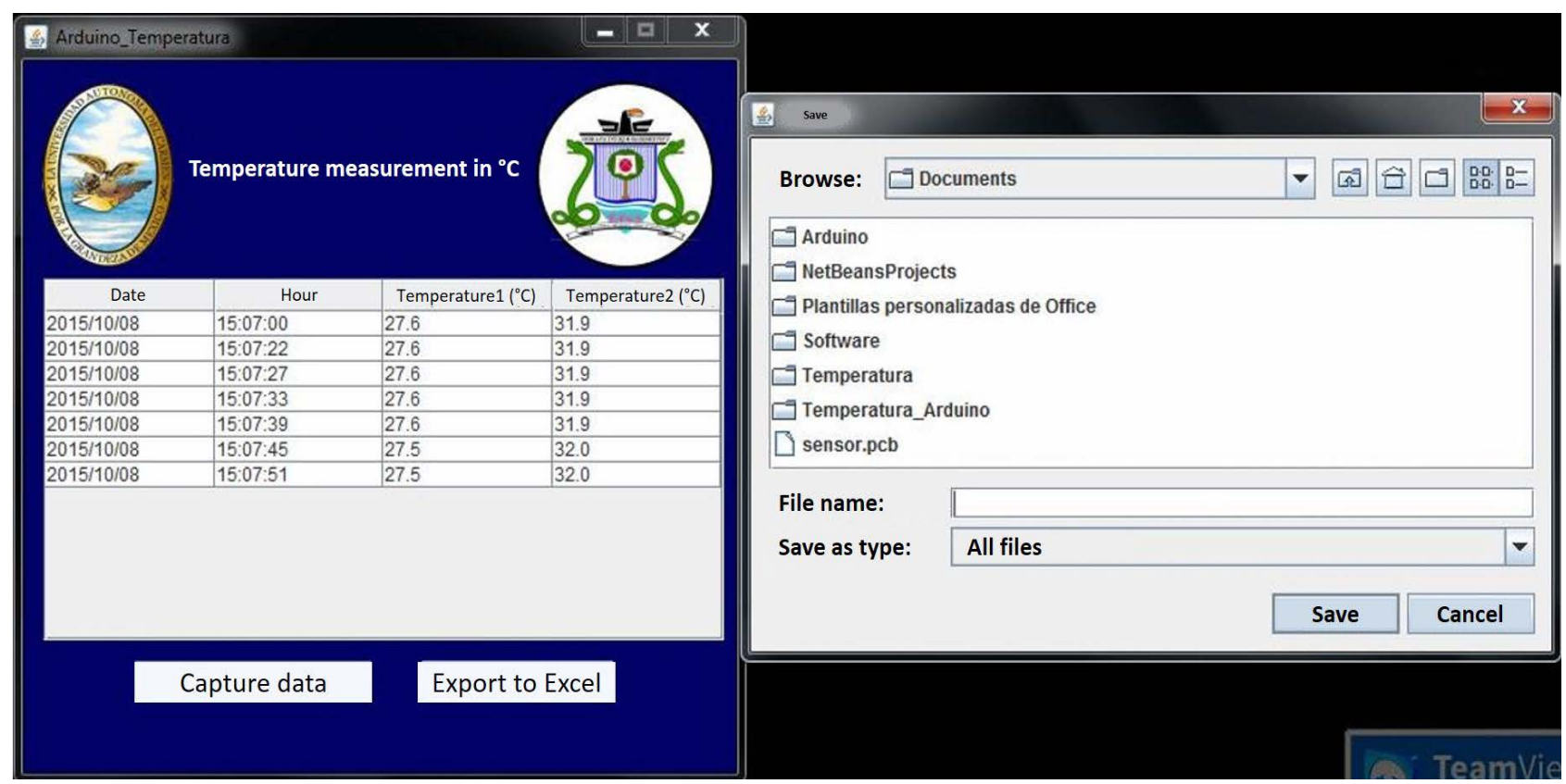

Figure 26. Application for temperature measurement characterization and its excel backup. 

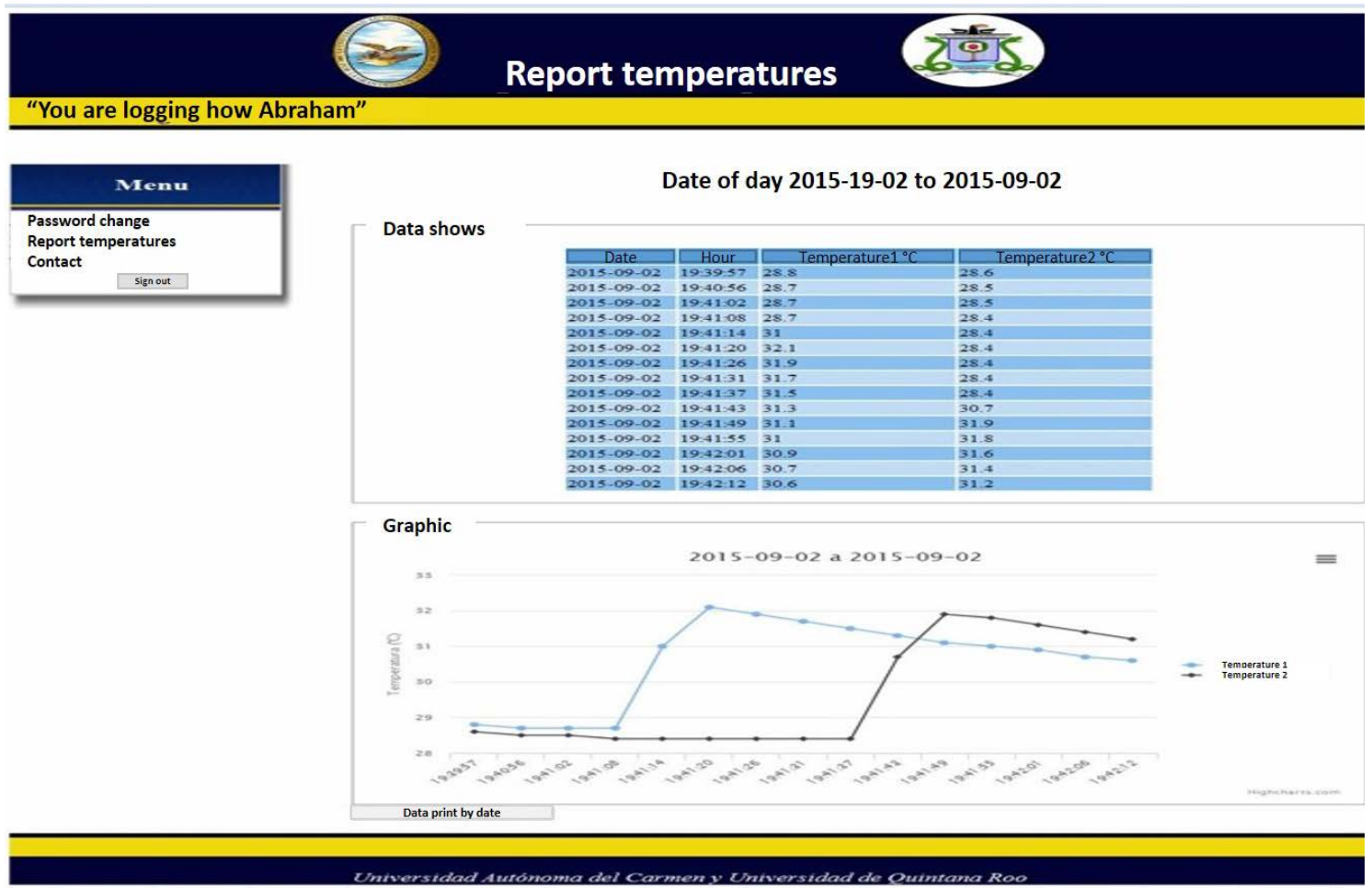

Figure 27. Advanced research motor made how web page.

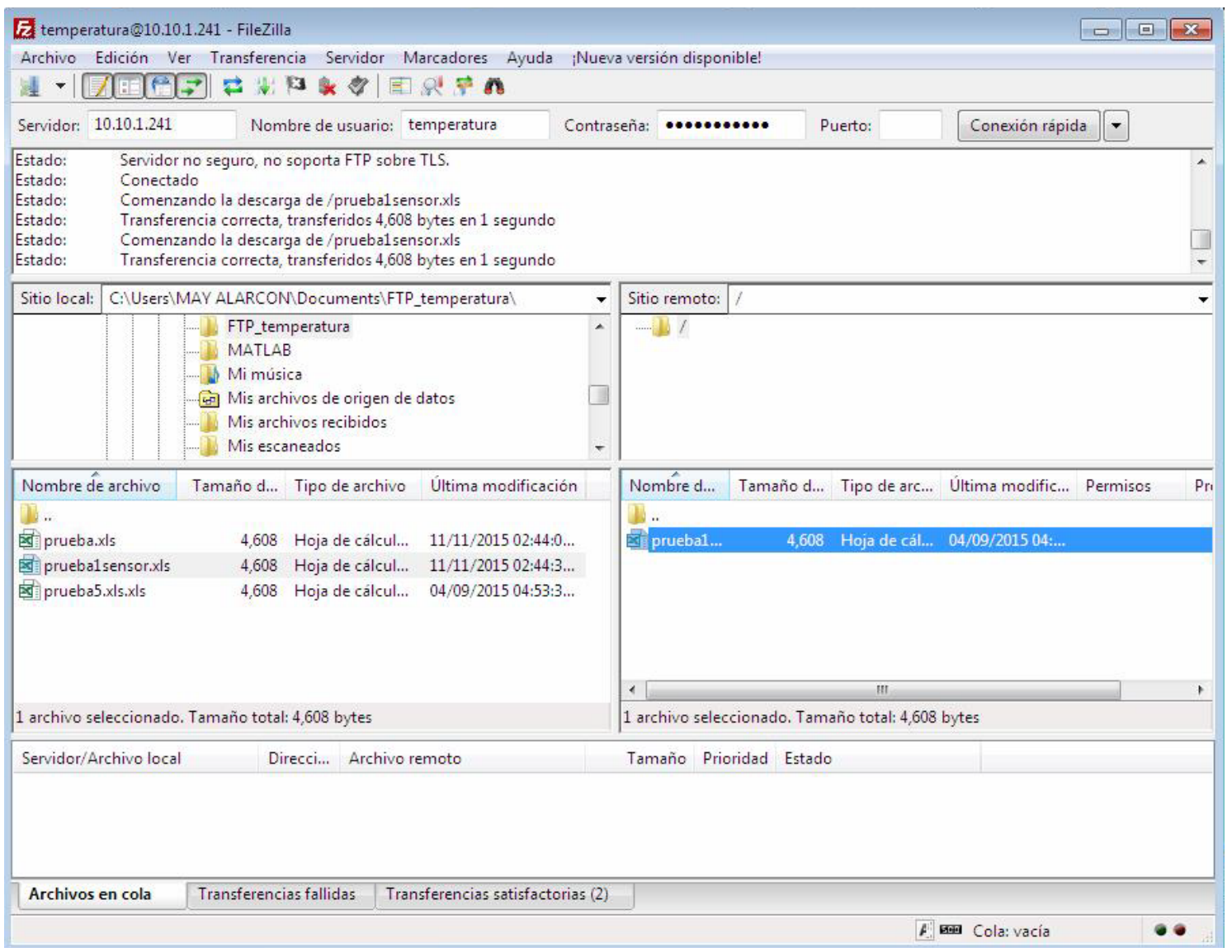

Figure 28. File transfers from the FTP server to client computer inside local area network. 


\section{Conclusions}

The optical array used in this investigation is operated with a pump laser diode of $980 \mathrm{~nm}$, optical array EDFA with a Bragg grating of $1548.4 \mathrm{~nm}$, circulator and SI with a $\mathrm{Hi}-\mathrm{Bi}$ fibre.

The results of the ASE noise characterization were made to learn about the power of the general optical array, with the graphs the user can do comparisons as needed.

When optimizing the splices of the optical array and reducing the length of $\mathrm{Hi}$-Bi fibre to $0.16 \mathrm{~m}$, most of the ASE noise is removed, but if it is compared when the $\mathrm{Hi}$-Bi fibre had $0.22 \mathrm{~m}$, the power transmitted in $0.16 \mathrm{~m}$ is less, so the ASE peak noise is at $1531.8 \mathrm{~nm}$. Furthermore, when the Hi-Bi fibre was reduced to $0.16 \mathrm{~m}$ and then only signal at $1548.4 \mathrm{~nm}$ was let through by the SI.

Also, in this investigation the hardware and software of a system was implemented to work with detection, measurement, storage and remote acquisition of the variable temperature in a Hi-Bi fibre of an SI into the optical array. In order to make the detection and measurement of the variable temperature into the SI, it was needed to use different approaches and platform for its programming.

This investigation can be continued by removing most of the ASE noise in the EDFA, which is possible by changing the length of erbium doped fibre and parameters used in the SI. Also changing the temperature heating or cooling in the SI to find the taller valley in order to have more power and less ASE noise in the transmission, is desirable. The measurement of the system is possible by adding more sensors and editing the code. This system can work in different applications because it can be used on different surfaces.

\section{Acknowledgements}

Authors are grateful to IPN, SIP-IPN, CIITEC-IPN, UNACAR, Universidad de Quintana Roo and CONACYT, from MEXICO and Optical Sciences Group at Twente University in the Netherlands.

\section{Conflicts of Interest}

The authors declare no conflicts of interest regarding the publication of this paper.

\section{References}

[1] Mustapha Remouche, F.G. (2013) Stress Sensing by an Optical Fiber Sensor: Method and Process for the Characterization of the Sensor Response Depending on Several Designs. Optics and Photonics Journal, 10, 194-203. https://doi.org/10.4236/opj.2013.32032

[2] Mahdikhani, M. (2008) Application and Development of Fiber Optic Sensors in Civil Engineering. The 14th World Conference on Earthquake Engineering, Beijing, 12-17 October 2008, 1-8.

[3] Ashwin Gumaste, T.A. (2003) DWDM Network Designs and Engineering Solu- 
tions. United State of America, Indianapolis.

[4] Rottwitt, K., Bjarklev, A.O., Povlsen, J.H., Lumholt, O. and Rasmussen, T.P. (1992) Fundamental Design of a Distributed Erbium-Doped Fiber Amplifier for Long-Distance Transmission. Journal of Lightwave Technology, 10, 1544-1552. https://doi.org/10.1109/50.184892

[5] Albert, J. (2011) Fiber Bragg Grating Sensors: A look Back. In: Andrea Cusano, A.C., Ed., Fiber Bragg Grating Sensors, Carlton Publishing House, Carleton, 1-8.

[6] Qiao, X., Shao, Z., Bao, W. and Rong, Q. (2017) Fiber Bragg Grating Sensors for the Oil Industry. Sensors, 17, 429. https://doi.org/10.3390/s17030429

[7] Monzon, D., et al. (1997) Interferómetro de Sagnac con selectividad espectral. Revista Mexicana de Física, 43, 972-980.

[8] Dhokar, A. (2015) Design and Performance Analysis of Dynamic EDFA. IOSR Journal of Engineering (IOSRJEN), 5, 23-33.

[9] Fideromo Saavedra, G., Dante Leonelli, Z. and Álvaro Lamas, N. (2005) Propagación de pulsos ópticos a travéz de amplificadores de fibra dopada con erbio (EDFA). Revista Facultad de Ingeniería-Universidad de Tarapacá, 13, 82-88. https://doi.org/10.4067/S0718-13372005000300012

[10] Kaur, A. and Singh, J. (2012) Measurement of ASE in an In-Line EDFA. International Journal of Advanced Research in Computer Science and Electronics Engineering, 1, 190-198.

[11] Flores-Rosas, A., et al. (2008) Eliminación de ruido ASE en una fibra dopada con erbio empleando un filtro basado en el interferómetro de Sagnac con fibras de Hi-Bi en el lazo. Revista Mexicana de Física, 54, 130-134.

[12] Do-Hyun, K. and Kang, J. (2004) Segnac Loop Interferometer Based on Polarization Maintanning Photonic Crystal Fiber with Reduced Temperature Sensitivity. Optics Express, 12, 4490-4495. https://doi.org/10.1364/OPEX.12.004490

[13] Ariel Leiva, L., Marco Tarifeño, G. and Ricardo Olivares, V. (2007) Effects of Polarization Mode Dispesion (PMD) on Propagation of Optical Pulses in Optical Fibers. Ingeniare: Revista chilena de ingeniería, 15, 336-343.

[14] Steinkamp, A., Vorbeck, S. and Voges, E.I. (2004). Polarization Mode Dispersion and Polarization Dependent Loss in Optical Fiber Systems, Optical Transmission Systems and Equipment for WDM Networking III. Proceedings of SPIE-The International Society for Optical Engineering, 5596, 1-12. 